\title{
Mechanisms Reducing ENSO Amplitude and Asymmetry via an Enhanced Seasonal Cycle in the Mid-Holocene
}

\author{
TOMOKI IWAKIRI AND MASAHIRO WATANABE \\ Atmosphere and Ocean Research Institute, The University of Tokyo, Tokyo, Japan
}

(Manuscript received 9 February 2019, in final form 4 July 2019)

\begin{abstract}
Paleo proxy records have suggested that El Niño-Southern Oscillation (ENSO) variability during the midHolocene [8200 to 4200 years ago (8.2-4.2 ka)] was weaker than during the instrumental periods, but the mechanisms remain unclear. We examined processes of ENSO suppression using a coupled general circulation model (CGCM) that simulates ENSO amplitude and skewness under the present climate reasonably well. Two long simulations were performed: one using the preindustrial condition (CTRL) and the other using the 8-ka insolation having a greater seasonal cycle (MH8K). Consistent with proxy records and previous modeling studies, the ENSO amplitude weakened by $20 \%$ in MH8K compared to CTRL, mainly because of reduced thermocline feedback during the mature and decay phases. The weak thermocline feedback, likely a result of the loose equatorial thermocline in the mid-Holocene, suppresses the occurrence of extreme El Niño events and consequently explains the reduction in both ENSO amplitude and asymmetry. In MH8K, strengthened trade winds over the western-central Pacific Ocean act to cool the surface via evaporation while warmer water in the southern subtropical Pacific is transported beneath the equatorial thermocline, both contributing to diffuse the thermocline. Multimodel simulations for the mid-Holocene showed mean state changes and ENSO weakening similar to MH8K, but most models did not show reduced ENSO skewness, probably because of the failure in reproducing extreme El Niño events under the present climate.
\end{abstract}

\section{Introduction}

El Niño-Southern Oscillation (ENSO) is the most prominent coupled atmosphere-ocean mode in the present climate system affecting weather conditions in many regions of Earth. ENSO has an oscillatory nature with a distinct life cycle; the essential mechanism is understood well via linear processes. However, recent studies have focused on the complexity of the observed ENSO events such as the irregularity and amplitude asymmetry between El Niño and La Niña (Capotondi et al. 2015; Timmermann et al. 2018). Regarding the asymmetry, several extreme El Niño events showing the sea surface temperature (SST) anomaly exceeding $+2 \mathrm{~K}$ in the eastern equatorial Pacific have been observed, but no such extreme La Niñas have occurred during the past century. Among processes that can produce the ENSO asymmetry, a nonlinear anomalous temperature advection in the upper ocean, termed nonlinear dynamical heating (NDH), is known to enhance the amplitude of El Niño while suppressing La Niña (Jin et al. 2003;

\footnotetext{
Corresponding author: T. Iwakiri, iwakiri@aori.u-tokyo.ac.jp
}

An and Jin 2004; Su et al. 2010). There are also other coupled feedbacks that can give rise to the positive skewness in the ENSO SST time series (Burgers and Stephenson 1999; Watanabe et al. 2011; Choi et al. 2013; An and Kim 2017; Hayashi and Jin 2017).

In addition to an inherent nonlinearity in the coupled processes, an interaction with a seasonal cycle can theoretically generate irregularity in the ENSO cycle (Jin et al. 1994; Tziperman et al. 1994; Steinke et al. 2014; Stein et al. 2014; Stuecker et al. 2015). Using an ensemble of coupled general circulation models (CGCMs), it has been claimed that the ENSO variability magnitude is inversely correlated with the seasonal cycle amplitude of mean SST across models, although the physical mechanism remains unclear (Guilyardi 2006; Guilyardi et al. 2009; An and Choi 2014). Furthermore, the role of the seasonal cycle in causing ENSO asymmetry has not been examined using CGCMs. The seasonal cycle in climate is ultimately maintained by a seasonal change in insolation, which has changed because of the Milankovitch forcing at millennial and longer time scales.

Investigating ENSO behavior under different climatic regimes compared to the present is useful in 
understanding ENSO dynamics' dependency on climatic mean states. A good example is the paleo ENSO during the mid-Holocene (8200-4200 years before the present), when the Northern Hemisphere received more insolation during summer and hence the seasonal cycle was stronger than that of the present era (Bradley 2003). Insolation changes modulate ENSO by altering the seasonal cycle of the tropical Pacific climate. In fact, paleo proxy records (e.g., fossil coral reconstructions) show that ENSO during the mid-Holocene was 20\%-60\% weaker in amplitude than that of the present day (Rein et al. 2005; Koutavas et al. 2006; Cobb et al. 2013; EmileGeay et al. 2016; Chen et al. 2016; Lu et al. 2018).

To understand the mechanisms of ENSO weakening during the mid-Holocene, many numerical studies have been done to date. Clement et al. (2000) reproduced an ENSO suppression using a simple coupled model under a mid-Holocene condition and suggested that enhanced mean trade winds acted to stabilize an ENSO-like oscillation. A similar conclusion was obtained from CGCM experiments (Luan et al. 2012). However, other mechanisms that weaken ENSO during the mid-Holocene have also been proposed: changes in the mean thermocline intensity (Liu et al. 2000, 2003), strengthened Asian summer monsoon (Zheng et al. 2008), decrease in annualmean SST (Roberts et al. 2014), stronger damping effect of meridional advection (An and Bong 2018), and greening of the Sahara altering the Walker circulation in the Pacific (Pausata et al. 2017).

As previously described, a synthetic understanding of the ENSO weakening mechanism during the midHolocene has not yet been achieved. Moreover, little attention has been paid to the extent by which ENSO asymmetry decreased during that period. Based on proxy records, Carré et al. (2014) suggested that ENSO was weak during the mid-Holocene not only in variance but also in skewness. This issue is challenging for GCMs because most models cannot reproduce El Niño-La Niña asymmetry seen in observations (Sun et al. 2016; Kohyama and Hartmann 2017).

In this study, we investigated the mechanisms of ENSO variability change during the mid-Holocene using a stateof-the-art CGCM that reproduces ENSO amplitude and asymmetry under the present climate. In particular, attempts were made to understand processes in which a change in mid-Holocene mean states modulate ENSO. This paper is organized as follows. In section 2, we describe the CGCM and numerical experiments and briefly introduce multimodel ensemble and observational datasets to compared to those of our CGCM experiments. Section 3 investigates changes in simulated ENSO characteristics under preindustrial and midHolocene conditions. In section 4, changes in the climatological mean state relevant to explaining the changing ENSO properties during the mid-Holocene are examined. The consistency and robustness of the results based on a single CGCM are discussed in section 5 by comparing them to multimodel simulations of the mid-Holocene. Section 6 provides a summary and discussion.

\section{Model, experiments, and data}

\section{a. 8-ka climate simulation using MIROC5.2}

We used an updated version of the Model for Interdisciplinary Research on Climate version 5 (MIROC5), cooperatively developed at the Atmosphere and Ocean Research Institute (AORI) of The University of Tokyo, the National Institute for Environmental Studies (NIES), and the Japan Agency for Marine Earth Science and Technology (JAMSTEC) (Watanabe et al. 2010). The model, termed MIROC5.2, has a horizontal resolution of T85 (approximately 150-km horizontal spacing) and 40 vertical levels up to $3 \mathrm{hPa}$ for the atmosphere. The ocean component model has a $1^{\circ} \times 1^{\circ}$ horizontal resolution and 63 vertical levels. The meridional grid points are doubled near the equator to better resolve equatorial ocean waves. MIROC5.2 simulates climate mean states similar to MIROC5 and has been extensively used for the attribution of twentieth-century climatic changes (Watanabe et al. 2014; Takahashi and Watanabe 2016).

Two 300-yr-long simulations were performed as follows: one was a preindustrial control experiment (hereafter CTRL) following the configuration of piControl in phase 5 of the Coupled Model Intercomparison Project (CMIP5; Taylor et al. 2012), and the other was a midHolocene experiment (hereafter MH8K), which was the same as CTRL except the orbital parameters (obliquity, eccentricity, and precession) were set at values from 8000 years ago (8-ka values; this format is used hereinafter) (Berger 1978). For all of the experiments, data for the initial 50 years, which we regarded as a spinup period, were discarded. Monthly anomalies are computed relative to the climatology for the entire period in CTRL and MH8K, respectively.

A change in orbital parameters alters the incoming insolation at the top of atmosphere (TOA) as shown in Fig. 1. During the mid-Holocene, the TOA insolation seasonal cycle strengthened over the Northern Hemisphere and at the equator (Fig. 1b). In addition, the annual-mean insolation increased over the extratropics whereas it slightly decreased over the tropics due to larger obliquity at $8 \mathrm{ka}$ (Fig. 1c). We conducted a preliminary test of repeating the 8-ka simulation with the obliquity parameter set at the preindustrial value; namely, the annual-mean change in insolation between 

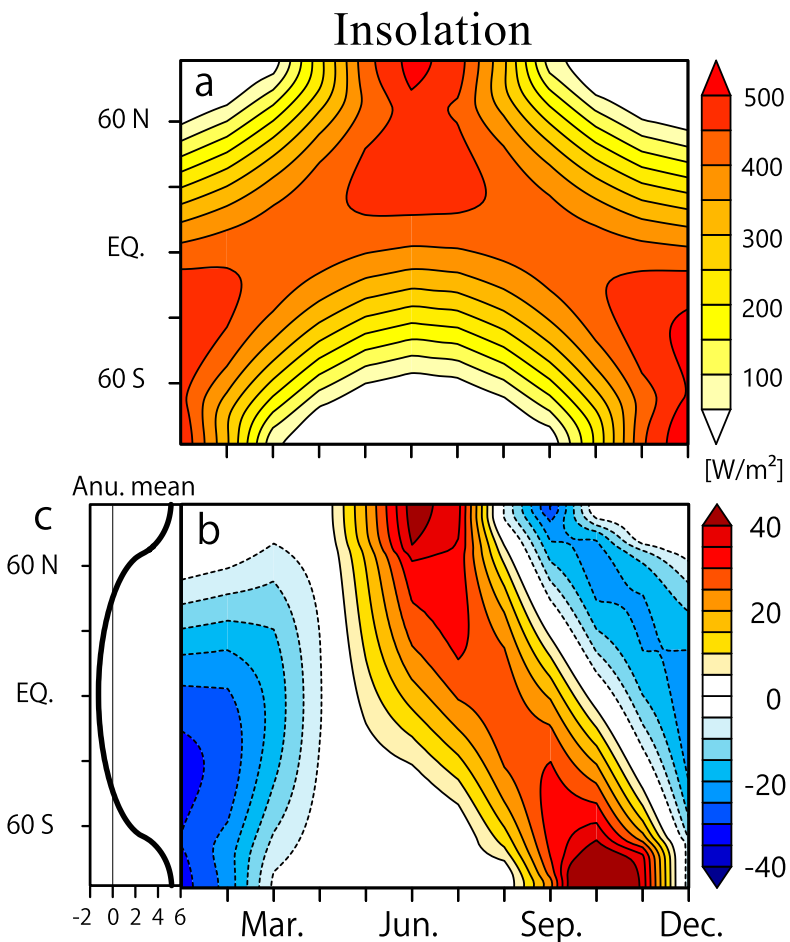

FIG. 1. Monthly evolution of TOA insolation in (a) CTRL and (b) the difference between MH8K and CTRL (former subtracting the latter). (c) The zonal and annual mean of (b). The unit is $\mathrm{W} \mathrm{m}^{-2}$.

the tropics and high latitudes diminished. The climate mean state in the tropics and the ENSO variability for that run were very similar to those for MH8K, confirming that the difference between CTRL and MH8K originates from the altered seasonal cycle in insolation induced by changes in eccentricity and precession, consistent with Erb et al. (2015).

We also performed another mid-Holocene experiment with 6-ka orbital parameters to compare the simulation to an existing multimodel ensemble of 6-ka simulations (Braconnot et al. 2012; cf. section 2b). The results from our 6-ka simulation were very similar to those of MH8K. This is not surprising because the difference in the TOA insolation between 6 and $8 \mathrm{ka}$ was small (Otto-Bliesner et al. 2003).

\section{b. Observations and CMIP5-PMIP3 multimodel ensemble data}

We use observed monthly SST datasets derived from COBE-SST2 (Hirahara et al. 2014), HadISST (Rayner et al. 2003), and ERSSTv5 (Huang et al. 2017) for the period from 1900 onward to verify climatological states and ENSO in the CTRL. Before the analysis, linear trends were removed at each grid point and anomalies were defined as a deviation from the monthly climatology for 1981-2010.
To discuss the robustness of the results based on a single model, we analyzed monthly outputs from nine CGCMs that participated in CMIP5 and phase 3 of the Paleoclimate Modeling Intercomparison Project (Braconnot et al. 2012). The models are as follows: CCSM4, CNRM-CM5, CSIRO-Mk3.6, GISS-E2-R, HadGEM2-ES, IPSL-CM5A-LR, MIROC-ESM, MPIESM-P, and MRI-CGCM3. For each model, the data are from two experiments: a 100-yr preindustrial control (taken from CMIP5) and 100-yr 6-ka simulations (taken from PMIP3). When comparing the MIROC5.2 midHolocene simulation to the PMIP3 runs as described in section 5, we used the results from the 6-ka simulation instead of those of MH8K.

\section{Mid-Holocene ENSO in MIROC5.2}

In this section, we compare the ENSO characteristics of the observations and two MIROC5.2 experiments. It is shown that the CTRL simulation reproduces the basic properties of the observed ENSO, namely the amplitude and asymmetry between El Niño and La Niña, both of which are significantly weakened in the MH8K. We then explore the coupled atmosphere-ocean feedback processes responsible for the change in ENSO during the mid-Holocene by means of a linear stability analysis and a low-order ENSO model.

\section{a. Weakening of ENSO}

Figure 2 shows the interannual SST variability represented by the standard deviation of the monthly SST anomalies in the tropical Pacific. The spatial pattern and magnitude in CTRL are similar to those of the observations except for an overly strong variability near the date line. In MH8K, it is evident that the SST variability is reduced in the equatorial central-eastern Pacific. The difference in the SST variability between CTRL and MH8K, associated with ENSO, is also seen in the power spectra and time series of the SST anomaly averaged in the Niño-3 $\left(5^{\circ} \mathrm{S}-5^{\circ} \mathrm{N}, 90^{\circ}-150^{\circ} \mathrm{W}\right)$ region (hereafter termed the Niño-3 index) (Fig. 3). Observations of COBE-SST2 show ENSO amplitude and asymmetry (measured by skewness) of $0.79 \mathrm{~K}$ and 0.74 for the period 1900-2017 (Fig. 3b). The large positive skewness is owing to several extreme El Niño events such as those during 1982/83, 1997/98, and 2015/16. We confirmed the values in other observational data: $0.76 \mathrm{~K} / 0.76$ in HadISST and $0.85 \mathrm{~K} / 0.62$ in ERSSTv5, which were only slightly different from the result of COBE-SST2. MIROC5.2 in CTRL which reproduced a realistic amplitude $(0.67 \mathrm{~K})$ and asymmetry $(0.70)$ similar to those of the observations. Occurrence of extreme El Niño events, interdecadal amplitude modulation, and 


\section{SST Standard deviation}
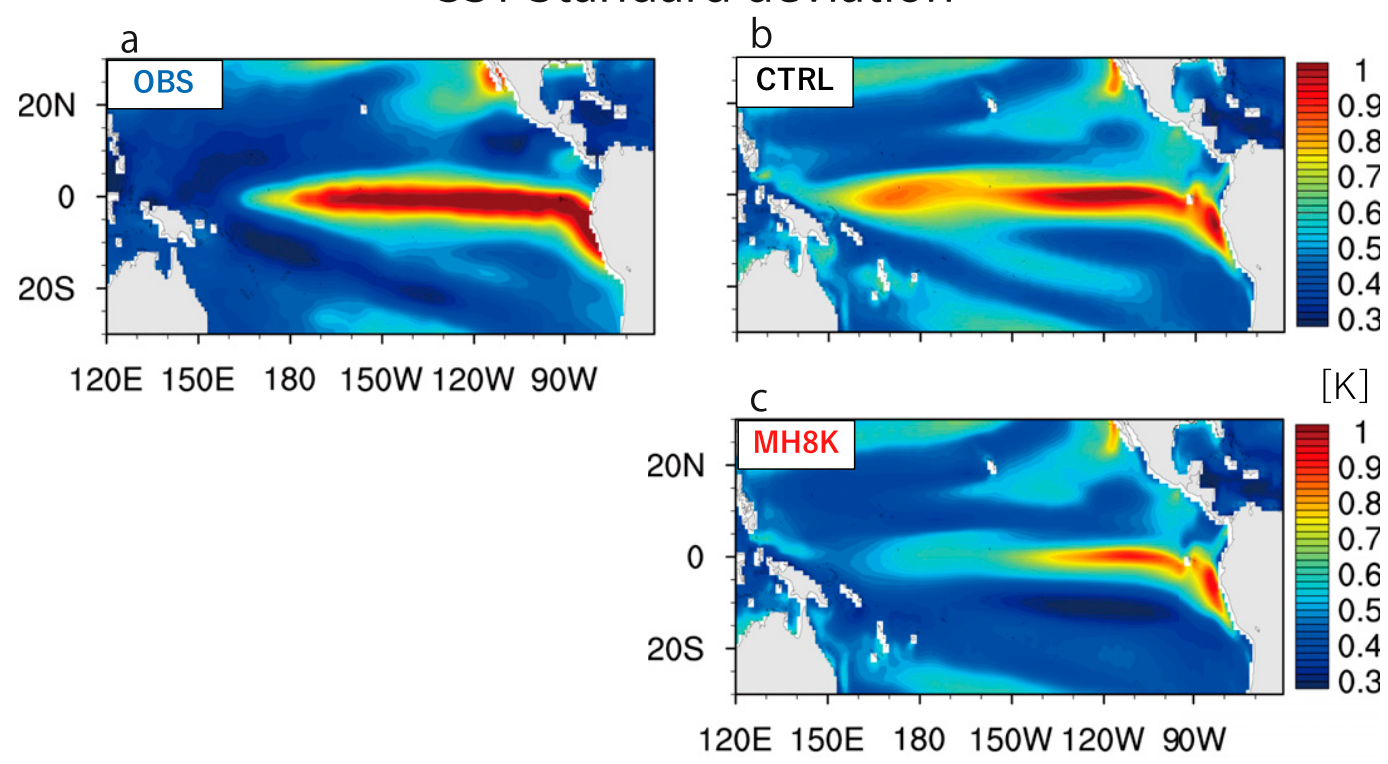

FIG. 2. Standard deviations of monthly SST anomalies in the tropical Pacific for (a) observations (COBE-SST2) during the period 1900-2017, (b) CTRL, and (c) MH8K. The unit is K.

periodicity are also reasonably well captured (Fig. 3). In MH8K, the amplitude was $0.52 \mathrm{~K}$, a decrease of $22 \%$, and the skewness was 0.31 , a decrease of $56 \%$ compared to CTRL. These changes are consistent with the proxy records. It is seen in Niño-3 index time series that extreme El Niño events rarely occurred in MH8K, resulting in weak asymmetry because of the El Niño and La Niña events.

A typical El Niño evolution is obtained by taking a monthly composite in equatorial SST anomalies during the El Niño events defined when the amplitude is greater than $0.5 \mathrm{~K}$ (red shading in Figs. $3 \mathrm{c}$ and $3 \mathrm{~d}$ ). ENSO in CTRL peaks during August-October, approximately three months earlier than the observed, such that we define the ENSO growth phase as MayJuly (MJJ), the mature phase as August-October (ASO), and the decay phase as November-January (NDJ) (Fig. 4a). The ENSO phase-locking feature does not change in MH8K (Fig. 4b). The difference in the composite SST anomalies between the two experiments shows that the ENSO weakening in the latter originates from the reduced amplitude of the positive SST anomalies from the mature to decay phases (Fig. 4c).

\section{b. Evaluating ENSO stability changes in the mid-Holocene condition}

Given that ENSO is a complex phenomenon containing various feedbacks in the coupled atmosphereocean system (Collins et al. 2010; Timmermann et al.
2018), it is useful to adopt a simple decomposition of processes that govern the growth and decay of $\mathrm{El}$ Niño events. Here, we use the so-called Bjerknes (BJ) coupled-stability index proposed by Jin et al. (2006). The BJ index is an extension of linear stability analysis for ENSO based on a linearized mixed-layer temperature equation in the eastern equatorial Pacific (Jin 1996), in which the ENSO growth rate [denoted as BJ in Eq. (1)] is expressed by a summation of five terms representing different coupled atmosphere-ocean feedback processes as follows:

$$
\begin{aligned}
2 \mathrm{BJ}= & -\left(\frac{\Delta[\bar{u} a]_{\mathrm{EW}}}{L_{x}}+\frac{\Delta[\bar{v} a]_{\mathrm{NS}}}{L_{y}}\right)+\mu_{a} \beta_{u}\left\langle-\frac{\partial \bar{T}}{\partial x}\right\rangle_{E} \\
& +\mu_{a} \beta_{w}\left\langle-\frac{\partial \bar{T}}{\partial z}\right\rangle_{E}+\mu_{a} \beta_{h}\left\langle\frac{H(\bar{w}) \bar{w}}{H_{m}}\right\rangle_{E} a_{h}-\alpha_{s},
\end{aligned}
$$

where $T$ denotes the ocean mixed-layer temperature and $u, v$, and $w$ indicate anomalies in oceanic zonal, meridional, and vertical currents. The overbar represents monthly climatology and $\Delta[]_{\mathrm{EW}}$ is the difference between the eastern and western boundary values. Similarly, $\Delta[]_{\mathrm{NS}}$ is the difference between the northern and southern boundaries. An approximated relationship between anomalous temperature $T^{\prime}$ and $T^{\prime}$ at each boundary is represented by $a$. The bracket \langle\rangle$_{E}$ signifies an area-average over the eastern equatorial Pacific. The step function $H(x)$ ensures that only upstream vertical advection is taken into consideration. Other parameters 
a

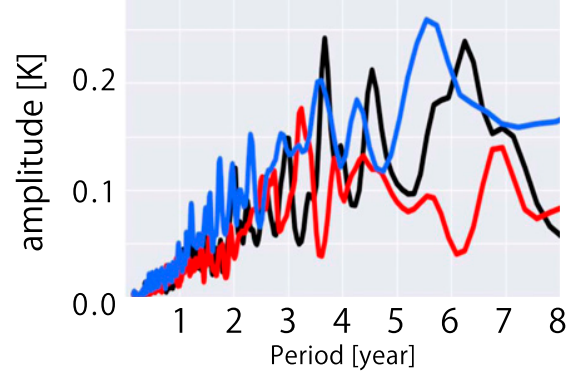

b ${ }_{3}$ OBS

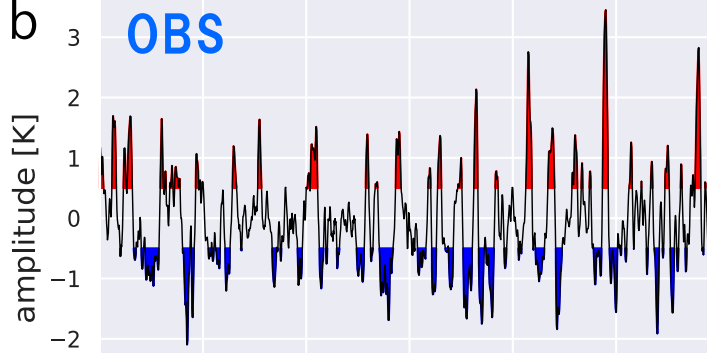

$-3 \quad \sigma=0.79 \quad$ skew $=0.74$

$1900 \quad 1940 \quad 1980$
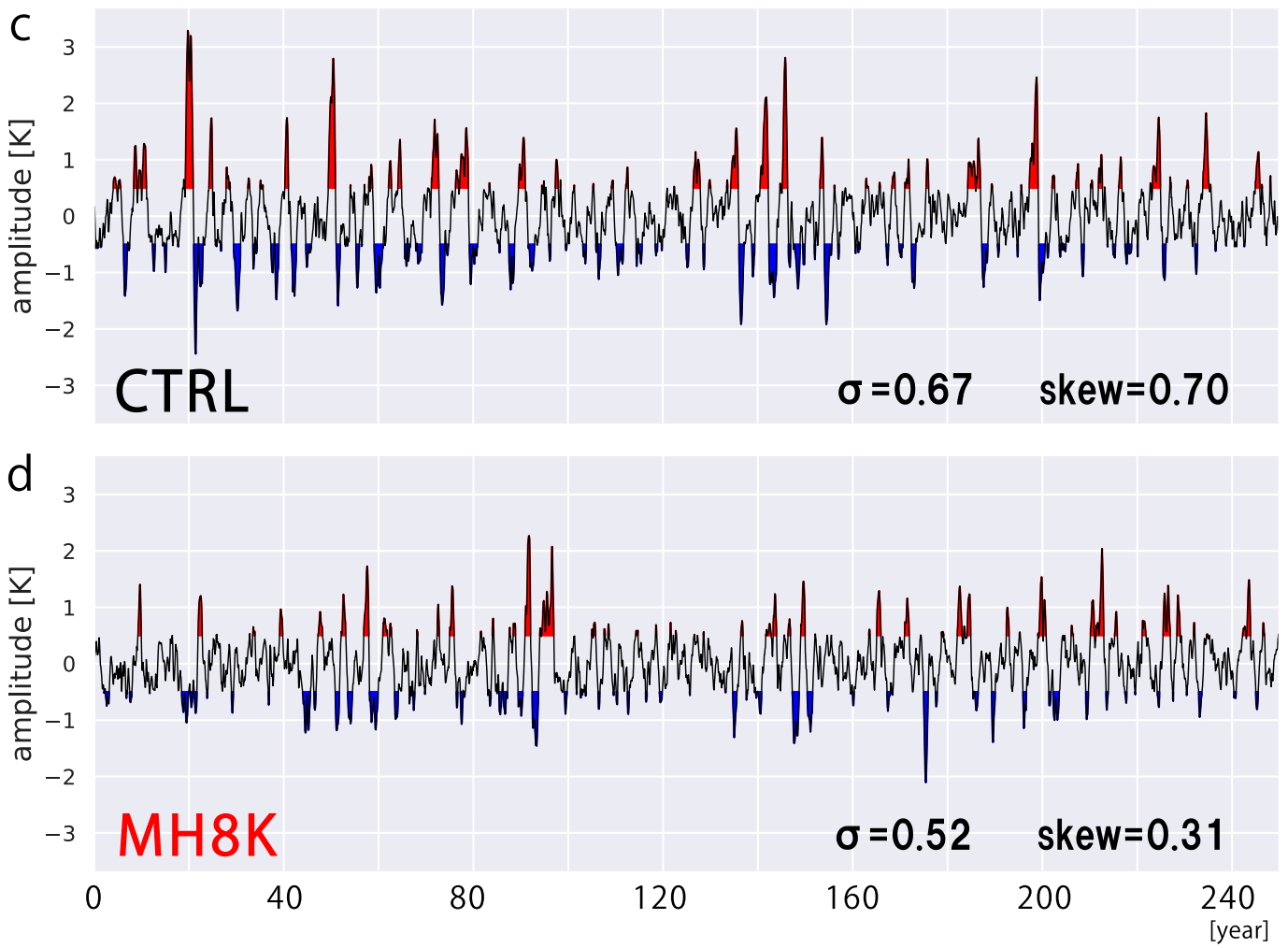

FIG. 3. (a) Power spectra of Niño-3 SST anomalies for COBE-SST2 (blue), CTRL (black), and MH8K (red), and (b)-(d) the corresponding time series. El Niño and La Niña events are indicated by red and blue shading, respectively. The standard deviation and the skewness are also shown.

are summarized in Table 1 . In terms of physical processes, the first two terms on the right-hand side represent the mean horizontal advection, which generally works as a negative feedback. Likewise, the third, fourth, and fifth terms represent zonal advective, Ekman, and thermocline feedback, respectively, all contributing to ENSO growth. The last term indicates a thermodynamic damping. The BJ index is advantageous because each term can be directly calculated from monthly outputs of the CGCMs and the sum of the terms is highly correlated with the ENSO amplitude in the CMIP5 models (Kim and Jin 2011a,b; Graham et al. 2014).
We can quantify the contribution of individual feedback processes to the evolution of ENSO in CTRL by calculating each term in Eq. (1) to which monthly anomalies as well as climatic mean states have been substituted (Fig. 5a). The BJ index in CTRL is very weakly unstable annually because of a strong thermocline feedback largely compensated by a combination of mean advection and thermal damping. The other two terms, zonal advection and Ekman feedback, are both positive but play a secondary role for the modeled ENSO to grow. All the terms show similar values for different seasons but the thermocline feedback shows a 


\section{El Niño composite of SST}
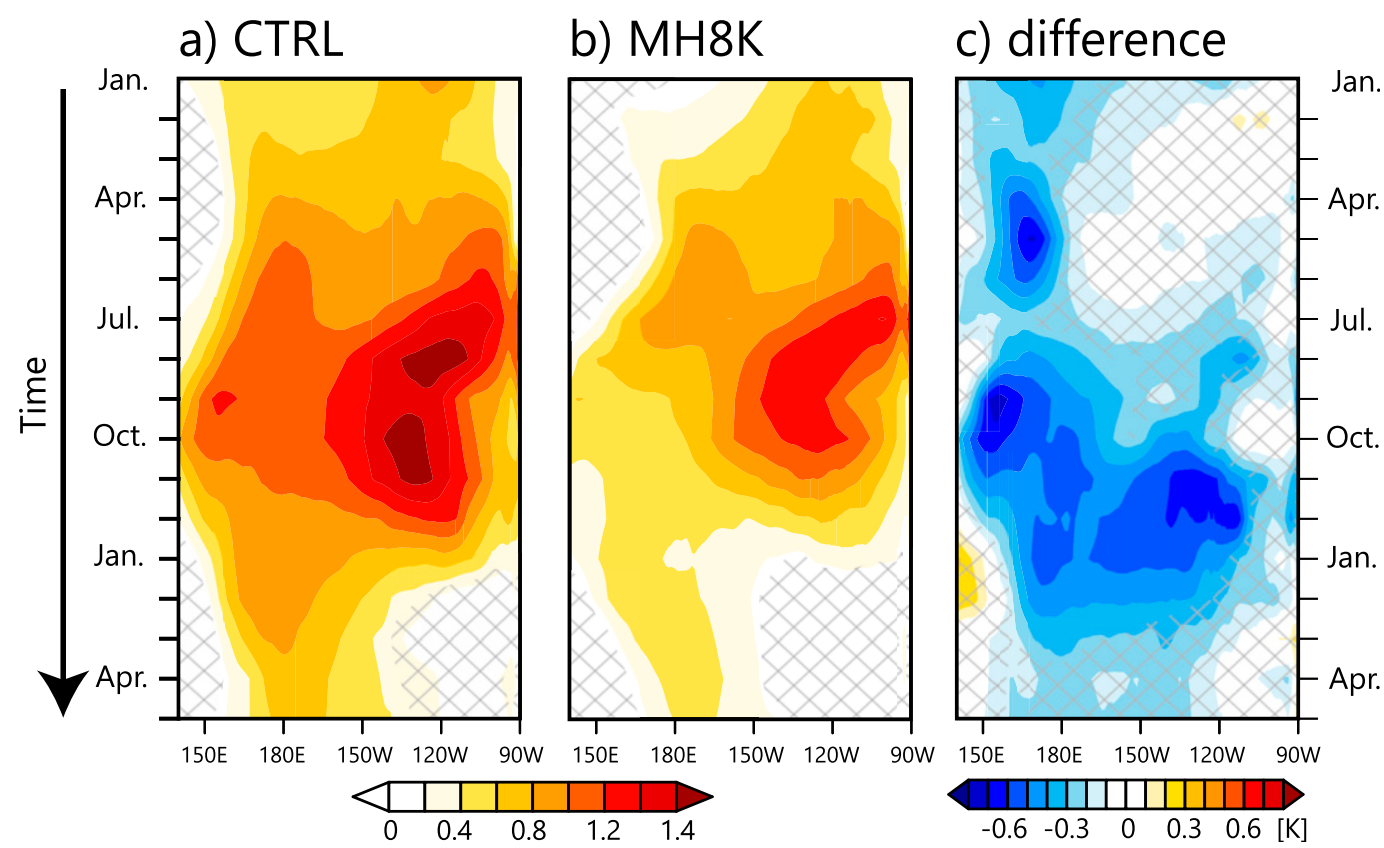

FIG. 4. (a),(b) Hovmöller diagrams of composite SST anomalies averaged over $2^{\circ} \mathrm{S}-2^{\circ} \mathrm{N}$ for El Niño in CTRL and MH8K, and (c) their difference (MH8K minus CTRL). Anomalies not significant at the $95 \%$ confidence level are hatched.

strong seasonality exciting the largest growth from MJJ to ASO, and thereby this term explains the simulated ENSO phase-locking feature (Fig. 5a).

In contrast to CTRL, the annual mean BJ index in MH8K is negative and suggests that the ENSO mode is weakly stable under the mid-Holocene condition (Fig. 5b). The largest difference in individual terms is found for the thermocline feedback, which decreased overall and was near neutral during ASO and NDJ. This weakened thermocline feedback is consistent with the El Niño composite evolution (Fig. 4b) and appears to explain its rapid decay in MH8K.

The thermocline feedback in Eq. (1) is represented by three parameters, $\mu_{a}$ (sensitivity of the trade wind response to $T$ ), $\beta_{h}$ (sensitivity of the thermocline slope to the anomalous wind), and $a_{h}$ (sensitivity of the subsurface temperature to the thermocline change) multiplied to the

TABLE 1. Parameters employed in the BJ index.

\begin{tabular}{ll}
\hline$L_{x}, L_{y}$ & Longitudinal and latitudinal length of the eastern box \\
$H_{m}$ & Mixed layer depth \\
$\mu_{a}$ & Wind stress response to SST \\
$\beta_{u}$ & Zonal current response to wind \\
$\beta_{w}$ & Upwelling response to wind \\
$\beta_{h}$ & Zonal slope of thermocline depth response to wind stress \\
$a_{h}$ & Subsurface temperature response to thermocline depth \\
$\alpha_{s}$ & Net surface heat flux anomaly respones to SSTA
\end{tabular}

mean upwelling velocity $\bar{w}$. Because $\mu_{a}$ and $\bar{w}$ are similar to each other for CTRL and MH8K (not shown), we compared the other two sensitivity parameters (Fig. 6). As expected, both parameter values in $\mathrm{MH} 8 \mathrm{~K}$ are small compared to those in CTRL: a $20 \%$ reduction in $\beta_{h}$ and $10 \%$ reduction in $a_{h}$. However, the scatterplots show considerable deviations for the individual anomalies from the regression lines, for CTRL in particular (Figs. 6a,c). These are mainly because of extreme El Niño events (defined as a Niño-3 index greater than 2 SD) that accompany large positive $\left(h_{E}-h_{w}\right)$ and $T_{\text {sub }}$ (indicated by red dots) values. When we remove those events to calculate the regression slopes in CTRL, the $\beta_{h}$ and $a_{h}$ values are quite similar to those in MH8K. This result implies that the thermocline feedback weakening in the linear BJ

TABLE 2. Values of each term in the BJ index for composite El Niño events in CTRL and MH8K.

\begin{tabular}{lrrrrrrrr}
\hline & \multicolumn{3}{c}{ All data } & & \multicolumn{3}{c}{ Without extreme events } \\
\cline { 2 - 3 } \cline { 6 - 7 } & CTRL & MH8K & Diff & & CTRL & MH8K & Diff \\
\hline MA & -0.98 & -1.01 & -0.03 & & -1.02 & -1.01 & 0.01 \\
TD & -0.57 & -0.63 & -0.06 & & -0.57 & -0.63 & -0.06 \\
ZA & 0.24 & 0.18 & -0.06 & & 0.22 & 0.17 & -0.05 \\
TH & 1.12 & 0.92 & -0.2 & & 0.87 & 0.82 & -0.05 \\
EK & 0.33 & 0.32 & -0.01 & & 0.33 & 0.33 & 0 \\
BJ & 0.14 & -0.22 & -0.36 & & -0.17 & -0.32 & -0.14 \\
\hline
\end{tabular}




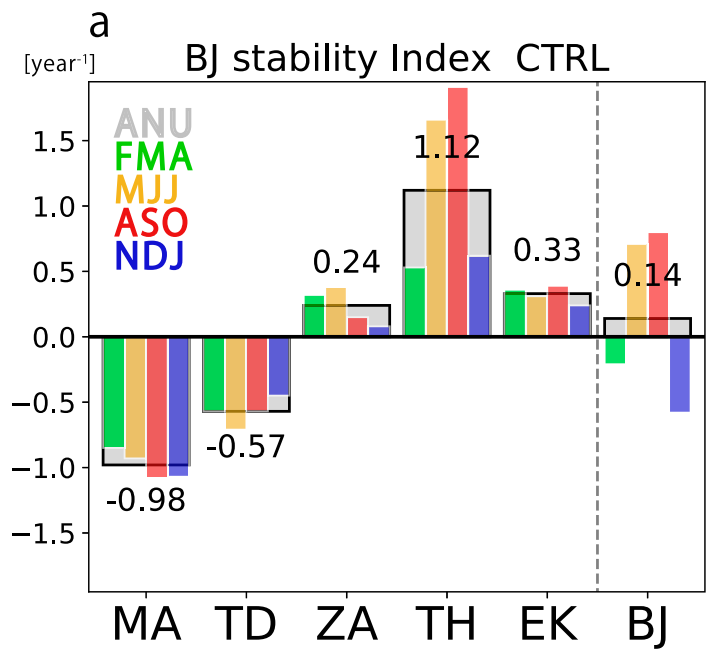

b

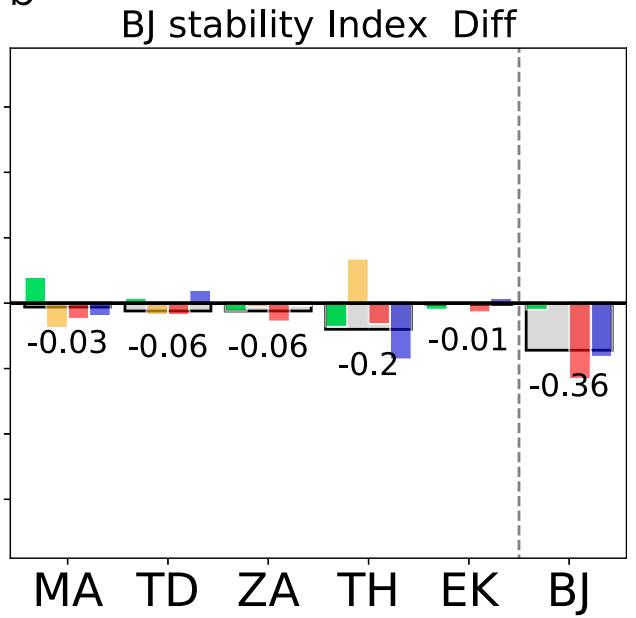

FIG. 5. (a) Individual terms of the BJ stability index (growth rate per year) for El Niño events in CTRL: MA (mean advection), TD (thermal damping), ZA (zonal advection), TH (thermocline feedback), EK (Ekman feedback), and BJ (total). Thick gray bars with numbers indicate the annual-mean values, which are divided into the contributions of each season by thin green, yellow, red, and blue bars. (b) As in (a), but for the difference between MH8K and CTRL.

index is actually because of the suppression of extreme El Niño events that presumably occurred in a nonlinear fashion. Accordingly, TH terms largely weakened from -0.2 to -0.05 , explaining $75 \%$ of the suppression (Table 2). We calculated the BJ index without extreme events, and the results showed a $60 \%$ weakening.

\section{c. Mechanism of ENSO weakening}

As shown in Fig. 6, the cause of the weak positive thermocline feedback in MH8K may be nonlinear as the diminished extreme El Niño events changed sensitivity parameters $\left(\beta_{h}\right.$ and $\left.a_{h}\right)$ and hence the thermocline feedback in the BJ index. Because the BJ index does not indicate which part of the mean state change is responsible for suppressing extreme El Niño events, we extended our analysis to a fully nonlinear framework that was able to explicitly simulate such events.

For the aforementioned purpose, we employed a loworder model by Timmermann et al. (2003). This model is a nonlinear extension of the recharge oscillator equations (Jin 1997) and can reproduce higher-order ENSO behavior such as El Niño-La Niña asymmetry as follows:

$$
\begin{aligned}
& \frac{d T_{1}}{d t}=-\alpha\left(T_{1}-T_{r}\right)-\frac{u\left(T_{2}-T_{1}\right)}{(L / 2)}, \\
& \frac{d T_{2}}{d t}=-\alpha\left(T_{2}-T_{r}\right)-\frac{w\left(T_{2}-T_{\text {sub }}\right)}{H_{m}},
\end{aligned}
$$

where $T$ represents ocean temperature in an equatorial box (subscripts 1 and 2 indicate the western and eastern Pacific, respectively). Parameters in this model are summarized in Table 3. The eastward current $u$ and vertical current $w$ are represented as follows:

$$
\begin{gathered}
u /(L / 2)=\epsilon \beta \tau_{1}, \\
w / H_{m}=-\zeta \beta \tau_{2} .
\end{gathered}
$$

The equatorial zonal wind stress, $\tau$, is proportional to the east-west temperature gradient and varies with the seasonal cycle as follows:

$$
\tau_{i}=\mu\left(T_{1}-T_{2}\right)\left[\gamma \cos \left(\omega_{a i} t-\phi_{i}\right)-1\right] / \beta \quad(i=1,2)
$$

where $\omega_{a}$ and $\phi$ indicate the annual cycle frequency and phase, respectively. The subsurface temperature $T_{\text {sub }}$ follows a parameterization in the original recharge model of Jin (1996) as follows:

$$
T_{\text {sub }}=T_{r}-\frac{T_{r}-T_{r 0}}{2}\left[1-\tanh \left(\frac{H+h_{2}-z_{0}}{h^{*}}\right)\right]
$$

The typical values of parameters follow Timmermann et al. (2003) $\left(T_{r 0}=16^{\circ} \mathrm{C}, T_{r}=29.5^{\circ} \mathrm{C}, \alpha=1 / 180\right.$ day $^{-1}$, $r=1 / 400 \mathrm{day}^{-1}, H_{m}=50 \mathrm{~m}, H=100 \mathrm{~m}, z_{0}=75 \mathrm{~m}, h^{*}=$ $62 \mathrm{~m}, \mu=0.0026 \mathrm{~K}^{-1} \mathrm{day}^{-1}, \mu b L / \beta=22 \mathrm{~m} \mathrm{~K}^{-1}, \zeta=1.3$, $\gamma=0.2, \varepsilon=0.1$, and $L=15 \times 10^{6} \mathrm{~m}$ ). The low-order model is integrated for 80 years, a sufficiently long period as the irregularity resulting from the stochastic process has not been incorporated.

There are several parameters that control the behavior of the low-order model. While Timmermann 

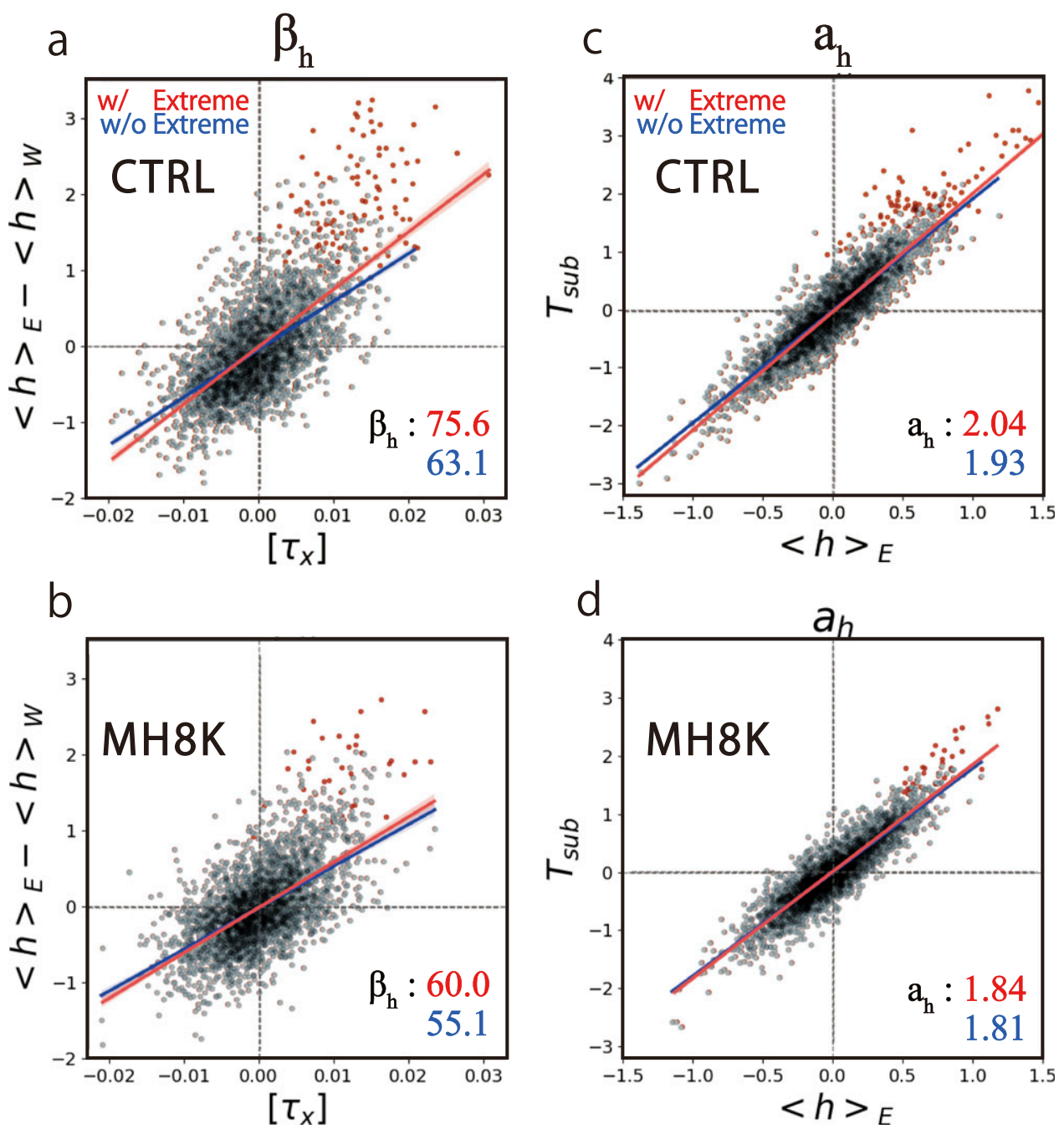

FIG. 6. Scatterplots between monthly anomalies associated with the thermocline feedback in the BJ index [see Eq. (1)]. (a),(b) Zonal thermocline slope $\left(h_{E}-h_{W}\right)$ against the Niño-4 zonal wind stress $\left(\left[\tau_{x}\right]\right)$ in CTRL and MH8K, respectively. (c),(d) Subsurface temperature ( $\left.T_{\text {sub }}\right)$ against the thermocline depth in the eastern equatorial Pacific $\left(h_{E}\right)$ in CTRL and MH8K, respectively. Dots and the regression line for all the available data are shown in red and those excluding extreme El Niño events are shown in blue in (a) and (c). The regression slopes represent the sensitivity parameters, $\beta_{h}$ and $a_{h}$, respectively, and the values are shown in the panels.

et al. (2003) perturbed three parameter $(\epsilon, \zeta$, and $\gamma$; see Table 3 for their meaning) to investigate the stability of ENSO-like solutions, we adopted another parameter representing the mean thermocline sharpness, $h^{*}$ [cf. Eq. (7)], as a controlling factor based on a finding by Meehl et al. (2001), who noted that the mean thermocline intensity is proportional to the ENSO amplitude in CGCMs because the less intense thermocline results in a colder temperature anomaly transported to the surface layer via windinduced upwelling. Furthermore, it is expected that the altered vertical temperature gradient associated with the change in the mean thermocline intensity modulates the vertical component of NDH, affecting the ENSO asymmetry.
Time series of the eastern Pacific temperature, $T_{2}$, using the typical values of $h^{*}$ are presented in Fig. 7a (black curve), which shows an intermittent "El Niño burst" occurring consistent with observations and MIROC5.2 CTRL. When a larger value of $h^{*}$ is adopted, the bursting disappears and the amplitude of the ENSO-like solution is smaller (Fig. 7a, red curve). We examined the change in the amplitude and asymmetry of the ENSO-like solution in the low-order model by calculating the standard deviation and skewness of $T_{2}$ using 80 different values of $h^{*}$ from 50 to $90 \mathrm{~m}$ (Figs. 7b,c). It is clearly seen that the larger value of $h^{*}$ corresponding to a more diffusive thermocline leads to a 
weaker amplitude as well as a smaller skewness for the ENSO-like oscillations. We can project the ENSO property in CTRL and MH8K on the diagram from the low-order model by estimating $h^{*}$ for the GCM. Following Meehl et al. (2001), we defined the thermocline intensity as the vertical thickness of isothermal layers between $16^{\circ}$ and $22^{\circ} \mathrm{C}$ at the equator, $155^{\circ} \mathrm{W}$, giving the values of $84.8 \mathrm{~m}$ in CTRL and $103.7 \mathrm{~m}$ in MH8K, respectively (a large value representing a weak thermocline). While the difference in thermocline intensity is consistent with the result of the low-order model, we cannot directly adopt them as $h^{*}$ because the thermocline intensity defined in this manner is not identical to the thermocline sharpness assumed in Eq. (7). Therefore, we regarded the typical value $\left(h^{*}=62.0 \mathrm{~m}\right)$ as a parameter for CTRL and a value factorized with the ratio of the intensity in MH8K against CTRL $\left(h^{*}=75.8 \mathrm{~m}\right)$ as a parameter for MH8K (dashed lines in Figs. 7b and 7c). The amplitude and skewness obtained from CGCM correspond reasonably well with the predicted value from estimated $h^{*}$ and the linear regressions by the low-order ENSO model (star symbols in Fig. 7). However, the change of $\beta_{h}$ in the BJ index is not well represented in the low-order model, and therefore the results might be overfitted.

The mechanisms of the mean thermocline intensity controlling the ENSO asymmetry were thus supported by parameter experiments using the nonlinear loworder ENSO model, and the weakened ENSO variability during the mid-Holocene can be plausibly explained by the change in mean thermocline intensity, which can indeed be seen in MH8K, as will be shown in the next section.

\section{Mean-state changes in the mid-Holocene condition}

Analyses of the time evolution of simulated El Niño events and their stability suggest that the amplitude reduction in MH8K can be attributed to the change in the mean thermocline structure, specifically the diffusive thermocline during the mid-Holocene. We explored how this change was induced by a larger seasonal cycle in insolation.

\section{a. SST and surface winds}

Changes in mean SST and surface winds in MH8K compared to CTRL are shown for each season in Fig. 8. In some areas in the Northern Hemisphere, such as the northern Indian Ocean and Caribbean Sea, mean SST is higher during the boreal summer and lower during the boreal winter, manifesting a direct response to the enhanced seasonal cycle in insolation (Fig. 1). A suppressed seasonal cycle of mean SST in the eastern equatorial Pacific is also confirmed in MH8K (see
TABLE 3. Parameters in the low-order ENSO model.

\begin{tabular}{ll}
\hline \hline $1 / \alpha$ & Thermal damping time scale \\
$T_{r}$ & Radiative-convective temperature \\
$L$ & Basin width \\
$H_{m}$ & Mixed layer depth \\
$\epsilon$ & Strength of zonal current \\
$\zeta$ & Strength of upwelling \\
$\mu$ & Sensitivity of the trade wind to the zonal SST gradient \\
$\gamma$ & Strength of annual cycle \\
$\omega_{a}$ & Annual cycle frequency \\
$T_{r}$ & Temperature beneath the thermocline \\
$H$ & Reference depth \\
$z_{0}$ & Depth at which $w$ takes its characteristic values \\
$h^{*}$ & Thermocline sharpness (intensity) \\
$B$ & Efficiency of wind stress \\
$R$ & Dynamical adjustment time scale \\
\hline
\end{tabular}

also Fig. 9). These characteristics are consistent with previous studies (Liu and Xie 1994; Liu et al. 2014; Braconnot et al. 2012; Erb et al. 2015; Lu and Liu 2019). However, the mean SST in the western equatorial Pacific changes does not totally follow the insolation change; it decreases the most during ASO when the trade winds intensify (Fig. 8c). A lower SST and stronger winds are reminiscent of the strengthened wind-evaporation-SST feedback at work during ASO and NDJ in this region. Overall, the SST seasonal cycle in the equatorial Pacific is weakened whereas the Walker circulation is not simply weakened as well but is shifted westward (Fig. 9). Because the equatorial surface zonal wind follows the zonal SST gradient, a negative zonal gradient between the Indian Ocean and western Pacific is consistent with a stronger easterly wind. Thus, the intensified westerncentral Pacific mean winds during ASO are likely induced by warming in the Indian Ocean (Fig. 8c).

\section{b. Upper ocean structure}

Sections $3 \mathrm{~b}$ and $3 \mathrm{c}$ described how the change in thermocline feedback that is critical to suppressing ENSO during the mature season was related to the change in the mean thermocline intensity (Figs. $5 \mathrm{~b}$ and 7 ). We therefore compared the equatorial upper-ocean temperature and thermocline intensity during ASO between CTRL and MH8K (Fig. 10). The equatorial thermocline is defined as the layer having the maximum vertical temperature gradient, which occurs at approximately the $20^{\circ} \mathrm{C}$ isoline in both experiments.

As expected, the thermocline is less sharp in MH8K between $160^{\circ} \mathrm{E}$ and $120^{\circ} \mathrm{W}$. Indeed, the thermocline intensity as define by Meehl et al. (2001) was reduced by $22 \%$ in MH8K (cf. section 3c). Although the result is not shown, the change in thermocline intensity is not 
a
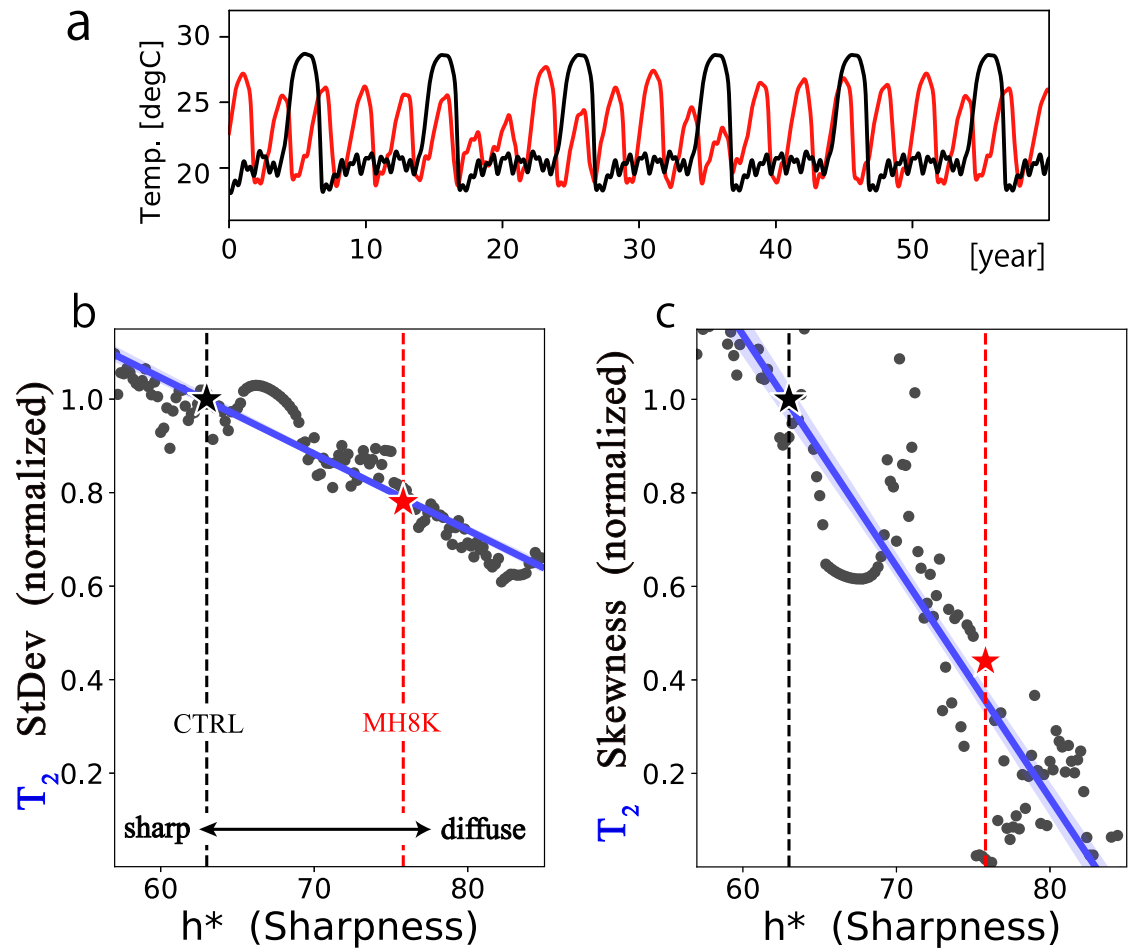

FIG. 7. (a) Time series of oceanic temperature in the eastern equatorial Pacific $\left(T_{2}\right)$ in the loworder ENSO model, with a standard value for the thermocline sharpness $h^{*}(62.0 \mathrm{~m}$; black) and a larger value representing a diffuse thermocline $(75.8 \mathrm{~m}$; red). (b) Standard deviation and (c) skewness of $T_{2}$, as a function of $h^{*}$. Each dot was calculated using the 60-yr time series of the model using a varying value of $h^{*}$ and normalized with respect to the standard case. The linear regressions are shown by the blue lines. Black and red dashed lines with star symbols represent the values corresponding to MIROC5.2 CTRL and MH8K, respectively.

significant during March-May, which is the period during which ENSO evolution is similar between CTRL and MH8K (Figs. 4b and 5b).

The weak thermocline in MH8K can be partly explained by the surface cooling during ASO that is associated with the strengthened trade winds (Fig. 8c). In addition, there is another process that warms the equatorial layer beneath the thermocline. It is well recognized that subsurface water is advected on isopycnal surfaces (Maes et al. 2002; Imada et al. 2016).
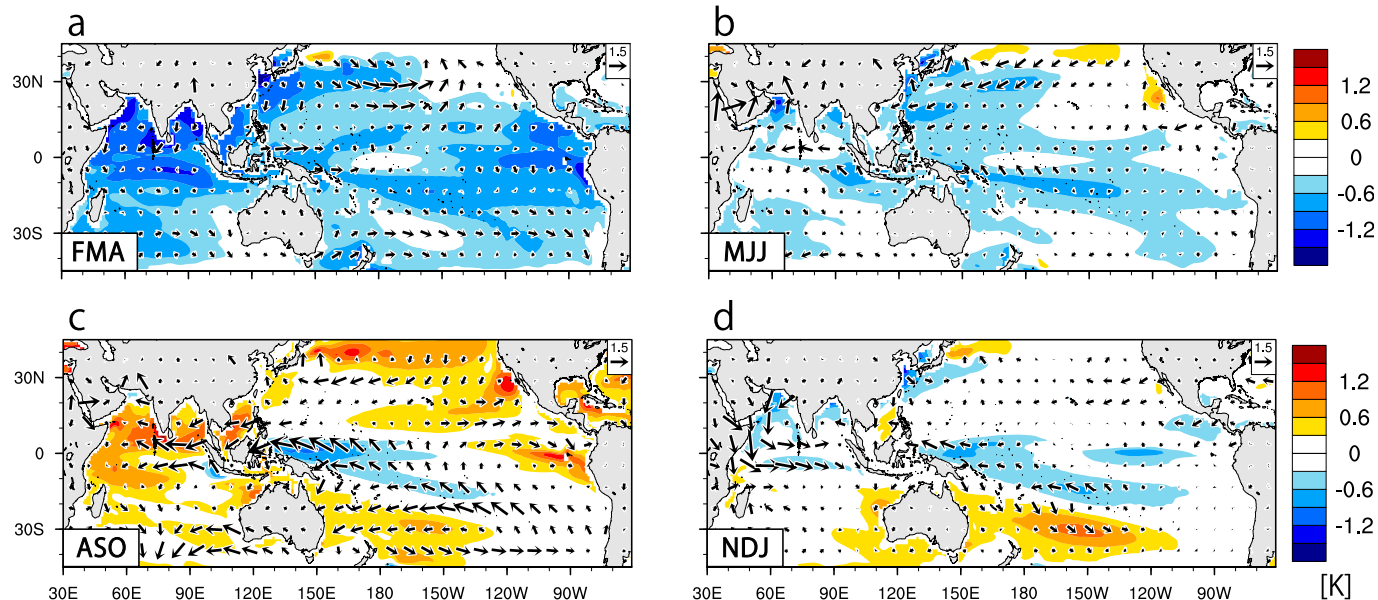

FIG. 8. Differences in the climatological mean SST (shading) and surface winds (vector; $\mathrm{m} \mathrm{s}^{-1}$ ) between CTRL and MH8K (latter minus former): (a) FMA, (b) MJJ, (c) ASO, and (d) NDJ. 


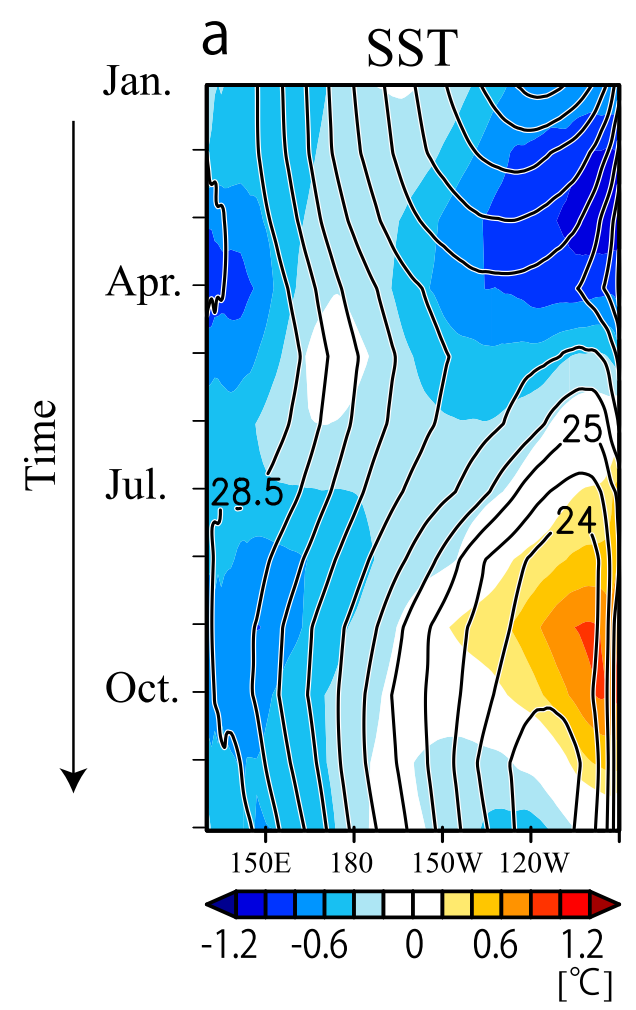

b $10 \mathrm{~m}$ zonal wind

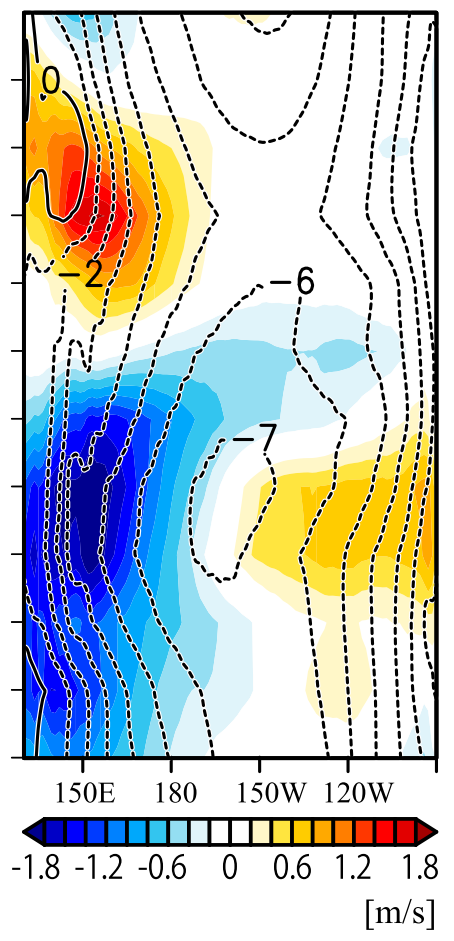

FIG. 9. Hovmöller diagram of the climatological seasonal cycle of (a) SST and (b) 10-m zonal wind averaged over $2^{\circ} \mathrm{S}-2^{\circ} \mathrm{N}$. Contours indicate values in CTRL and the shading represents the difference between MH8K and CTRL.

Thus, we observed annual-mean ocean states in the isopycnic coordinates. Figure 11a shows the vertical temperature gradient imposed on contours of potential density $\left(\sigma_{\theta}\right)$ in the west-central Pacific. It was found that the potential density layer between 25 and $26 \sigma_{\theta}$ lies immediately below the thermocline and is connected to the surface in the southern subtropics. A horizontal map of streamline in the 25-26 $\sigma_{\theta}$ isopycnal layer confirms that water at that depth can penetrate to the equator from $30^{\circ} \mathrm{S}$ in contrast to the northern subtropics where the isopycnal layer does not outcrop (Fig. 11). The oceanic flow from the northern subtropics toward the equator is obscure because the thermal structure associated with the intertropical convergence zone inhibits it (Lu et al. 1998). Subducted water from the mixed layer to the equatorial subsurface has a strong seasonality, which occurs only in late winter, called "Stommel's demon" (Stommel 1979; Schneider et al. 1999; Williams et al. 1995). These subsurface characteristics are represented well in coupled GCMs (Liu et al. 2000, 2003). Coincidently, mean SST during late winter increased in the southern subtropics where the 25-26 $\sigma_{\theta}$ isopycnal layer reaches the surface (shading in Fig. 11b, adopted from Fig. 8). While this process bringing warmer subsurface water is at work throughout the year, the weakened thermocline intensity is clear in ASO because of a combined effect with the surface layer cooling. In summary, the weak intensity of the mean thermocline in MH8K is coupled with two types of changes in the surface climate; stronger trade winds over the western-central Pacific and warming in the southern subtropical Pacific.

\section{Mid-Holocene ENSO in the CMIP5-PIMP3 multimodel}

\section{a. ENSO changes in 6-ka simulations}

In the previous sections, we clarified the ENSO weakening mechanism in the MIROC5.2 mid-Holocene simulation. Because the results are based on a single GCM and given the diversity of ENSO simulations in current GCMs (Bellenger et al. 2014; Chen et al. 2017), it is necessary to discuss the robustness of the mechanism in a multimodel framework. For this purpose, we used 6-ka mid-Holocene simulations from nine GCMs in PMIP3 and additionally our 6-ka experiment that showed very similar behavior to that of MH8K (section $2 b$ ).

Changes in ENSO amplitude and asymmetry, measured by the standard deviation and skewness of the 

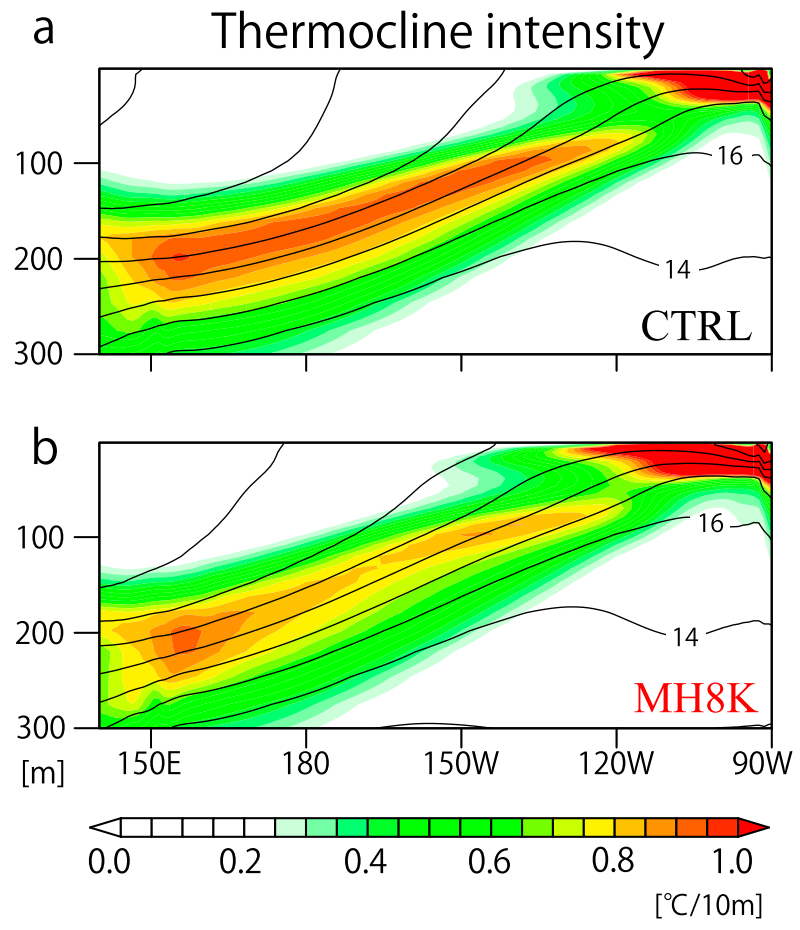

FIG. 10. Upper ocean temperature (contour) and its vertical gradient (shading) averaged over $2^{\circ} \mathrm{S}-2^{\circ} \mathrm{N}$ during ASO in (a) CTRL and (b) MH8K.

Niño-3 index as shown in Fig. 3, were compared among 10 models (Fig. 12). In the multimodel ensemble, 7 out of 10 models (all except for CSIRO-Mk3.6, MIROC-ESM, and MRI-CGCM3) show a reduction in the ENSO amplitude during the mid-Holocene, a robust feature across the models (see Fig. 12a and the values in Table 4). However, the El Niño-La Niña asymmetry weakens in some models but strengthens in others, such that the weakening of asymmetry found in MH8K is not common in the multimodel ensemble (Fig. 12b, Table 4). Yet, we may argue that the reduced El Niño-La Niña asymmetry identified in MH8K is a reliable change during the mid-Holocene because all but one of the PMIP3 models failed to reproduce the observed skewness in the preindustrial simulations. An exception is IPSL-CM5A-LR, which reproduced a realistic skewness near that of observations and the El Niño-La Niña asymmetry decreased in the 6-ka simulation as in MIROC5.2. Indeed, these two models show similar patterns of SST variability changes throughout the tropics between the two eras (cf. Fig. 2), suggesting that the mechanisms reducing ENSO amplitude and asymmetry described in the previous sections are also applicable to IPSL-CM5A-LR.

\section{b. Mean-state changes}

Changes in the climatological mean state between the preindustrial and 6-ka simulations in the PMIP3 models are shown in Fig. 13, which can be compared to Figs. 8 and 9 showing the MIROC5.2 experiments. In the multimodel ensemble mean, the suppressed seasonal cycle in the equatorial Pacific SST is very similar to the change in MH8K (Fig. 13a). In addition, the change in the seasonal cycle of zonal winds along the equator indicates stronger trade winds over the western-central Pacific during August and December (Fig. 13b). Figure 13d shows that the change in the ASO mean state (i.e., Indian Ocean warming and stronger trade winds) is robust; the latter probably acted to decrease SST in the western Pacific via enhanced evaporative cooling. In the southern subtropical
Potential density a Thermocline intensity

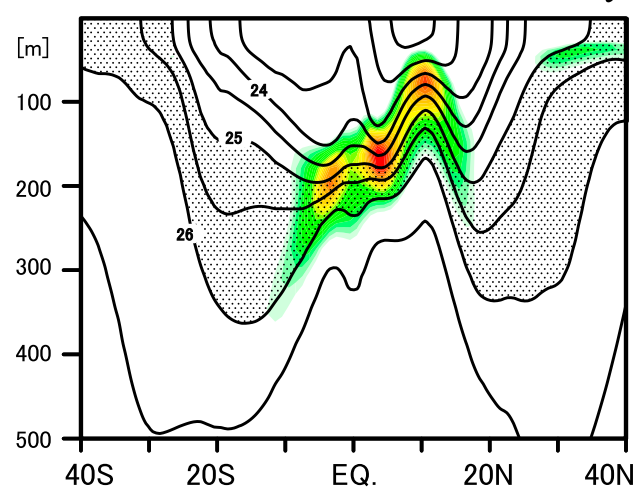

Stream line b (Isopycnal layer b/w 25-260 ${ }_{\theta}$ )

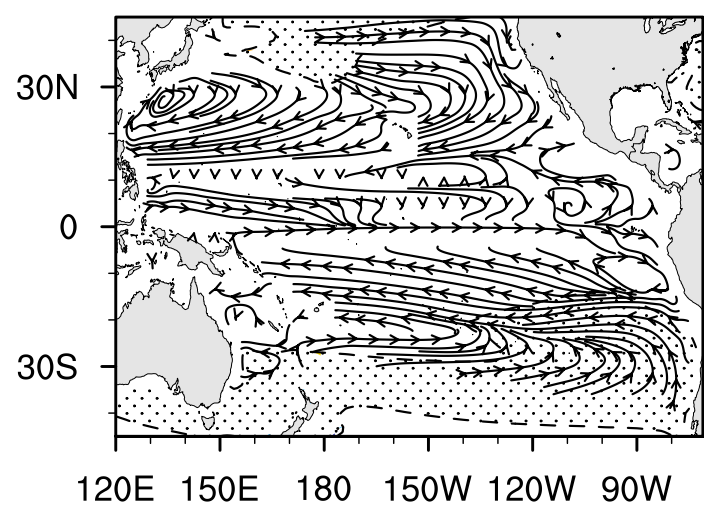

FIG. 11. (a) Latitude-depth cross section of the annual mean potential density ( $\sigma_{\theta}$; contour) and the vertical temperature gradient (shading) averaged over $160^{\circ} \mathrm{E}-150^{\circ} \mathrm{W}$ in MH8K. (b) Annual mean streamlines in MH8K, averaged in the $25-26 \sigma_{\theta}$ layer. Dots indicate the isopycnal layer between 25 and $26 \sigma_{\theta}$. 

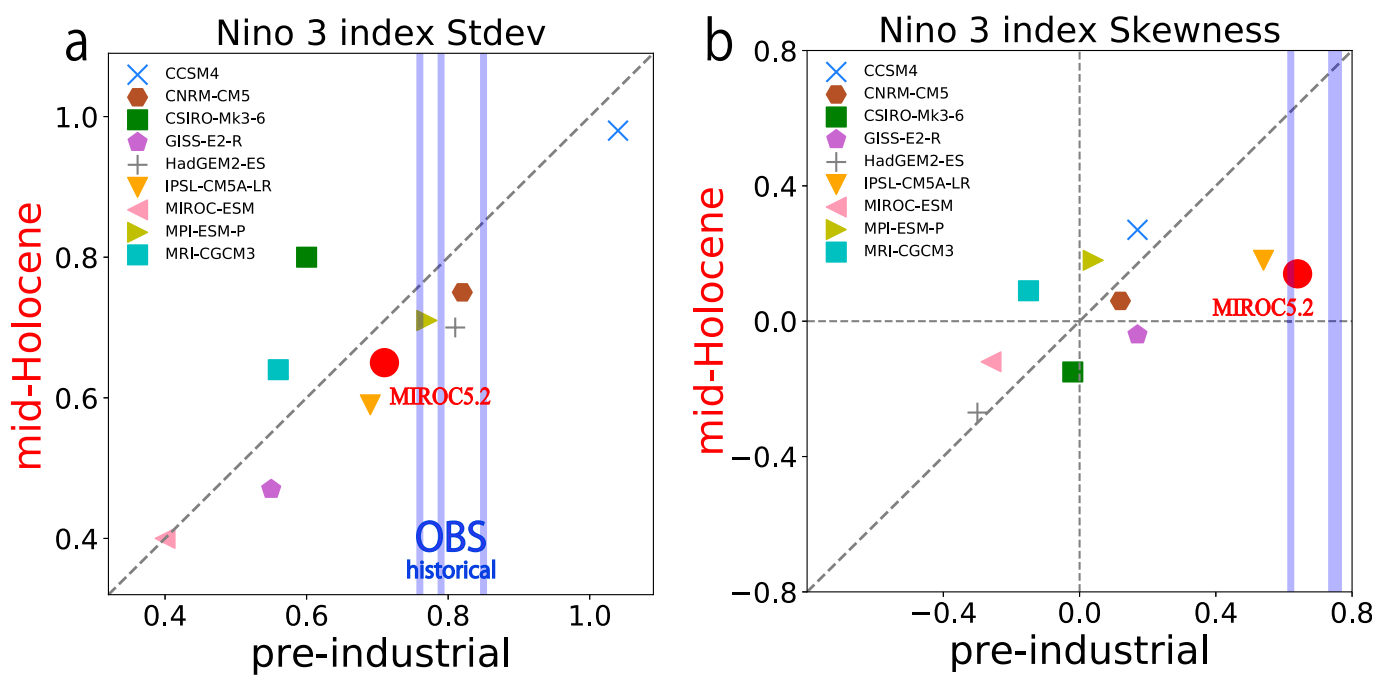

FIG. 12. Scatterplots of (a) standard deviation and (b) skewness in the Niño-3 index comparing the midHolocene and preindustrial simulations from nine CMIP5-PMIP3 models and MIROC5.2. Blue vertical lines indicate the values from three observational datasets (COBE-SST2, HadISST, and ERSSTv5) for the period 1900-2017.

Pacific, although the signal is weak, an increased SST was also found consistent with that of the MIROC5.2 experiment. Despite a similarity in the mean state changes between MH8K and PMIP3 models, many of the PMIP3 models do not show a systematic reduction in the ENSO skewness, probably because the skewness in the preindustrial run was too weak.

\section{Summary and discussion}

In the present study, we explored possible mechanisms of changing ENSO activity in the mid-Holocene by comparing two long climatic simulations using MIROC5.2 CGCM to preindustrial and 8-ka external conditions (i.e., CTRL and $\mathrm{MH} 8 \mathrm{~K}$, respectively).
Consistent with suggestions from paleo proxy records (e.g., Cobb et al. 2013; Carré et al. 2014; Lu et al. 2018), ENSO in MH8K was found to be weaker in amplitude by approximately $20 \%$ and in skewness by approximately $60 \%$ compared to that in CTRL.

The weakening occurs during the mature and decay phases of the ENSO cycle and the mechanism is schematically shown in Fig. 14. Increased boreal summer insolation during the mid-Holocene preferentially warms the Indian Ocean, which shifts the Pacific Walker circulation westward. The resultant enhanced easterly acts to decrease the mean SST in the western-central Pacific. Simultaneously, the mean SST increases in the southern subtropical Pacific, a region where surface water subducts and is transported to the equatorial subsurface

TABLE 4. Standard deviation and skewness values in the Niño-3 index in preindustrial (denoted as CMIP5) and 6-ka mid-Holocene (denoted as PMIP3) simulations from 10 CGCMs corresponding to Fig. 12.

\begin{tabular}{|c|c|c|c|c|c|c|}
\hline \multirow[b]{2}{*}{ Model } & \multicolumn{3}{|c|}{ Niño-3 std dev } & \multicolumn{3}{|c|}{ Niño-3 skewness } \\
\hline & CMIP5 & PMIP3 & Diff $(\%)$ & CMIP5 & PMIP3 & $\operatorname{Diff}(\%)$ \\
\hline CCSM4 & 1.04 & 0.98 & -5.77 & 0.17 & 0.27 & 58.82 \\
\hline CNRM-CM5 & 0.82 & 0.75 & -8.54 & 0.12 & 0.06 & -50.00 \\
\hline CSIRO-Mk3.6 & 0.60 & 0.80 & 33.33 & -0.02 & -0.15 & 650.00 \\
\hline GISS-E2-R & 0.55 & 0.47 & -14.55 & 0.17 & -0.04 & -123.53 \\
\hline HadGEM2-ES & 0.81 & 0.70 & -13.58 & -0.30 & -0.27 & -10.00 \\
\hline IPSL-CM5A-LR & 0.69 & 0.59 & -14.49 & 0.54 & 0.18 & -66.67 \\
\hline MIROC 5.2 & 0.71 & 0.65 & -8.45 & 0.65 & 0.14 & -78.46 \\
\hline MIROC-ESM & 0.40 & 0.40 & 0.00 & -0.26 & -0.12 & -53.85 \\
\hline MPI-ESM-P & 0.77 & 0.71 & -7.79 & 0.04 & 0.18 & 350.00 \\
\hline MRI-CGCM3 & 0.56 & 0.64 & 14.29 & -0.15 & 0.09 & -160.00 \\
\hline
\end{tabular}



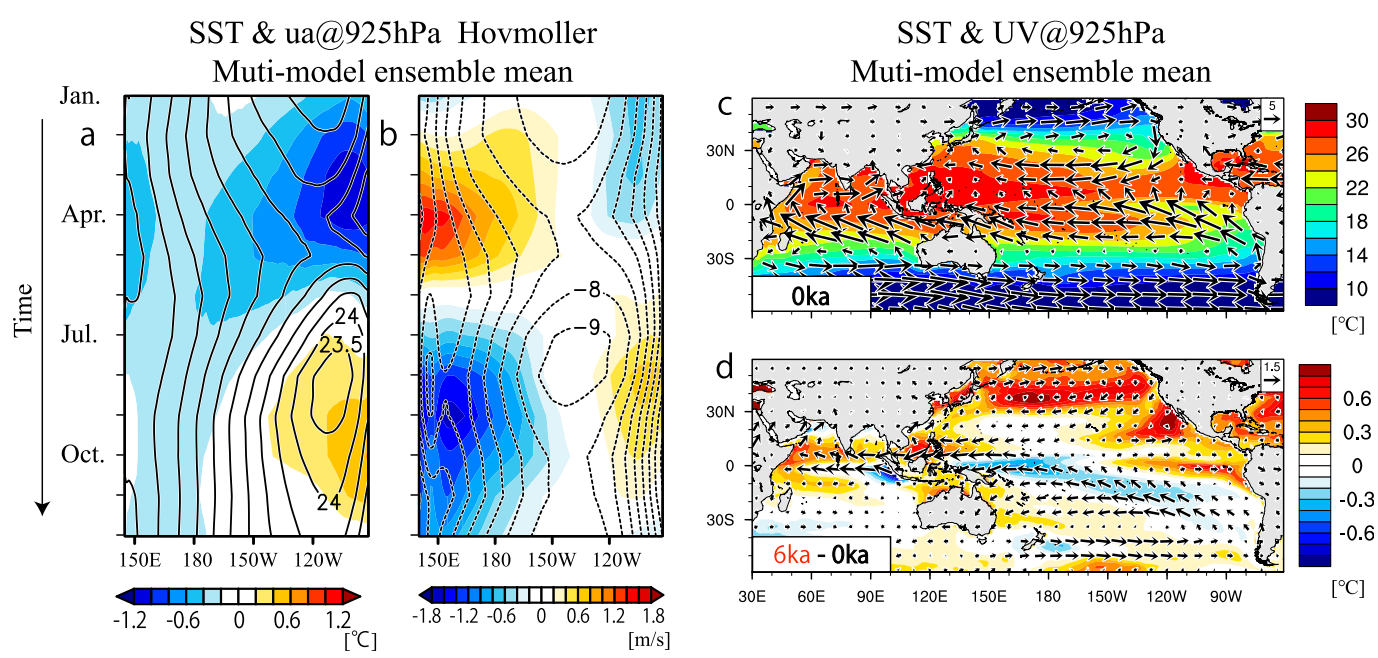

FIG. 13. (a),(b) As shown in Fig. 9, but the mean seasonal cycle in nine CMIP5-PMIP3 models. (c) Climatological mean SST and near-surface winds during ASO in the preindustrial simulations of the CMIP5-PMIP3 models and (d) their changes in the mid-Holocene simulations. All the values are the multimodel ensemble mean. The near-surface winds are based on winds at $925 \mathrm{hPa}$. Note that (d) corresponds to Fig. $8 \mathrm{c}$ in the MIROC5.2 MH8K experiment.

layer. Both the atmospheric and oceanic processes, although the former may be faster than the latter, thus act to mitigate the sharp equatorial thermocline. As supported by a low-order ENSO model, the occurrence of extreme El Niño events is suppressed with a diffusive mean thermocline, leading to a reduction in ENSO amplitude and asymmetry. In a linear stability analysis, the aforementioned process is interpreted as a positive thermocline feedback weakening.

The ensemble mean of the PMIP3 multimodels shows that the reduced ENSO amplitude and changes in mean states are similar to those identified in the MIROC5.2 experiments. However, the change in the El Niño-La Niña asymmetry varies across models. This probably is a result of the failure to reproduce the ENSO skewness under a preindustrial condition. Two models, MIROC5.2 and IPSL-CM5A-LR, which show a large skewness comparable to observations in their control runs, indeed show a reduction in ENSO asymmetry in the mid-Holocene simulations. We therefore conclude that reduced asymmetry should have occurred during the mid-Holocene via the previously explained mechanism. While current-generation models are not very good at reproducing the ENSO skewness (Sun et al. 2016; Liang et al. 2017; Ham 2017), CMIP6/PMIP4 models may be improved in this respect and it will therefore be worth revisiting this issue in future work.

The possibility that a diffusive thermocline caused a weak ENSO during the mid-Holocene has been discussed in Liu et al. (2000), but our results provide more detail, showing that both the amplitude and asymmetry reduction can be explained by a single mechanism. While several works have been completed addressing ENSO asymmetry under the present climate (An and Kim 2017; Hayashi and Jin 2017), limited work has been done to explore the relationship between its sensitivity and mean state change.

The ENSO suppression mechanism via an enhanced insolation seasonal cycle during the mid-Holocene may have an implication for ENSO in a warmer climate. In

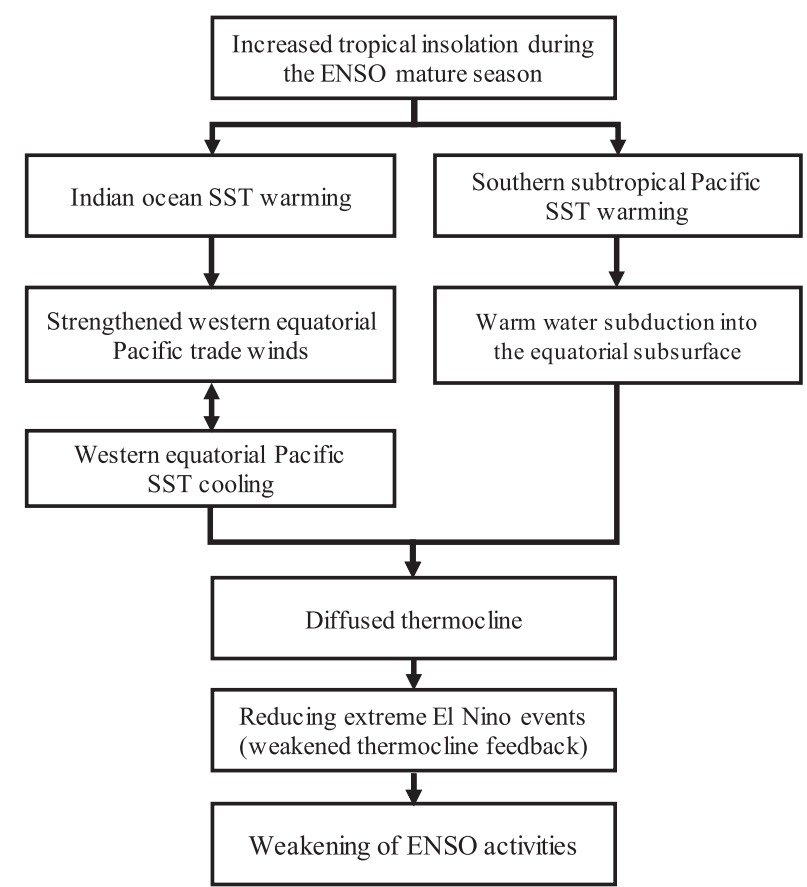

FIG. 14. Schematic diagram of the ENSO suppression mechanism during the mid-Holocene. 
fact, Kim et al. (2014), who analyzed future scenario simulations by CMIP5 models, showed that the ENSO activity may be weakened with the greenhouse warming, due to a weakening of the thermocline feedback. This is similar to what happened in our mid-Holocene experiment, although Kim et al. (2014) did not focus on changes in the seasonal cycle in the scenario experiments. Currently, possible future changes have been separately discussed in terms of ENSO activity (Cai et al. 2018) and the temperature seasonal cycle (Santer et al. 2018). They may actually be tied to one another, but further study is needed to synthetically understand the linkage between the seasonal cycle and ENSO in past and future climates.

Acknowledgments. We thank M. Kimoto, A. Oka, T. Kohyama, and anonymous reviewers for their constructive comments. This work was supported by the Integrated Research Program for Advancing Climate Models from the Ministry of Education, Culture, Sports, Science and Technology (MEXT), Japan.

\section{REFERENCES}

An, S.-I., and F.-F. Jin, 2004: Nonlinearity and asymmetry of ENSO. J. Climate, 17, 2399-2412, https://doi.org/10.1175/ 1520-0442(2004)017<2399:NAAOE $>2.0$.CO;2.

_- and J. Choi, 2014: Mid-Holocene tropical Pacific climate state, annual cycle, and ENSO in PMIP2 and PMIP3. Climate Dyn., 43, 957-970, https://doi.org/10.1007/s00382-013-1880-z.

_ sponse to wind on the asymmetrical transition of El Niño and La Niña. Geophys. Res. Lett., 44, 393-400, https://doi.org/ 10.1002/2016GL071971.

— , and H. Bong, 2018: Feedback process responsible for the suppression of ENSO activity during the mid-Holocene. Theor. Appl. Climatol., 132, 779-790, https://doi.org/10.1007/ s00704-017-2117-6.

Bellenger, H., E. Guilyardi, J. Leloup, M. Lengaigne, and J. Vialard, 2014: ENSO representation in climate models: From CMIP3 to CMIP5. Climate Dyn., 42, 1999-2018, https:// doi.org/10.1007/s00382-013-1783-z.

Berger, A. L., 1978: Long-term variations of daily insolation and quaternary climatic changes. J. Atmos. Sci., 35, 2362-2367, https:// doi.org/10.1175/1520-0469(1978)035<2362:LTVODI>2.0.CO;2.

Braconnot, P., S. P. Harrison, M. Kageyama, P. J. Bartlein, V. Masson-Delmotte, A. Abe-Ouchi, B. Otto-Bliesner, and Y. Zhao, 2012: Evaluation of climate models using palaeoclimatic data. Nat. Climate Change, 2, 417-424, https:// doi.org/10.1038/nclimate1456.

Bradley, R. S., 2003: Climate forcing during the Holocene. PAGES News, 11, 18-19, https://doi.org/10.22498/pages.11.2-3.18.

Burgers, G., and D. B. Stephenson, 1999: The "normality" of El Niño. Geophys. Res. Lett., 26, 1027-1030, https://doi.org/ 10.1029/1999GL900161.

Cai, W., and Coauthors, 2018: Increased variability of eastern Pacific El Niño under greenhouse warming. Nature, 564, 201-206, https://doi.org/10.1038/s41586-018-0776-9.
Capotondi, A., and Coauthors, 2015: Understanding ENSO diversity. Bull. Amer. Meteor. Soc., 96, 921-938, https://doi.org/ 10.1175/BAMS-D-13-00117.1.

Carré, M., J. P. Sachs, S. Purca, A. J. Schauer, P. Braconnot, R. A. Falcón, M. Julien, and D. Lavallée, 2014: Holocene history of ENSO variance and asymmetry in the eastern tropical Pacific. Science, 345, 1045-1048, https://doi.org/ 10.1126/science. 1252220 .

Chen, C., M. A. Cane, A. T. Wittenberg, and D. Chen, 2017: ENSO in the CMIP5 simulations: Life cycles, diversity, and responses to climate change. J. Climate, 30, 775-801, https://doi.org/ 10.1175/JCLI-D-15-0901.1.

Chen, S., S. S. Hoffmann, D. C. Lund, K. M. Cobb, J. Emile-Geay, and J. F. Adkins, 2016: A high-resolution speleothem record of western equatorial Pacific rainfall: Implications for Holocene ENSO evolution. Earth Planet. Sci. Lett., 442, 61-71, https:// doi.org/10.1016/j.epsl.2016.02.050.

Choi, K.-Y., G. A. Vecchi, and A. T. Wittenberg, 2013: ENSO transition, duration, and amplitude asymmetries: Role of the nonlinear wind stress coupling in a conceptual model. J. Climate, 26, 9462-9476, https://doi.org/10.1175/JCLI-D-1300045.1.

Clement, A. C., R. Seager, and M. A. Cane, 2000: Suppression of El Niño during the mid-Holocene by changes in the Earth's orbit. Paleoceanography, 15, 731-737, https://doi.org/10.1029/ 1999PA000466.

Cobb, K. M., N. Westphal, H. R. Sayani, J. T. Watson, E. Di Lorenzo, H. Cheng, R. L. Edwards, and C. D. Charles, 2013: Highly variable El Niño-Southern Oscillation throughout the Holocene. Science, 339, 67-70, https://doi.org/10.1126/science.1228246.

Collins, M., and Coauthors, 2010: The impact of global warming on the tropical Pacific Ocean and El Niño. Nat. Geosci., 3, 391397, https://doi.org/10.1038/ngeo868.

Emile-Geay, J., and Coauthors, 2016: Links between tropical Pacific seasonal, interannual and orbital variability during the Holocene. Nat. Geosci., 9, 168-173, https://doi.org/10.1038/ngeo2608.

Erb, M. P., A. J. Broccoli, N. T. Graham, A. C. Clement, A. T. Wittenberg, and G. A. Vecchi, 2015: Response of the equatorial Pacific seasonal cycle to orbital forcing. J. Climate, 28, 9258-9276, https://doi.org/10.1175/JCLI-D-15-0242.1.

Graham, F. S., J. N. Brown, C. Langlais, S. J. Marsland, A. T. Wittenberg, and N. J. Holbrook, 2014: Effectiveness of the Bjerknes stability index in representing ocean dynamics. Climate Dyn., 43, 2399-2414, https://doi.org/10.1007/ s00382-014-2062-3.

Guilyardi, E., 2006: El Niño-mean state-seasonal cycle interactions in a multi-model ensemble. Climate Dyn., 26, 329348, https://doi.org/10.1007/s00382-005-0084-6.

—, A. Wittenberg, A. Fedorov, M. Collins, C. Wang, A. Capotondi, G. J. van Oldenborgh, and T. Stockdale, 2009: Understanding El Niño in ocean-atmosphere general circulation models: Progress and challenges. Bull. Amer. Meteor. Soc., 90, 325-340, https://doi.org/10.1175/2008BAMS2387.1.

Ham, Y.-G., 2017: A reduction in the asymmetry of ENSO amplitude due to global warming: The role of atmospheric feedback. Geophys. Res. Lett., 44, 8576-8584, https://doi.org/ 10.1002/2017GL074842.

Hayashi, M., and F.-F. Jin, 2017: Subsurface nonlinear dynamical heating and ENSO asymmetry. Geophys. Res. Lett., 44, 12 427-12 435, https://doi.org/10.1002/2017GL075771.

Hirahara, S., M. Ishii, and Y. Fukuda, 2014: Centennial-scale sea surface temperature analysis and its uncertainty. J. Climate, 27, 57-75, https://doi.org/10.1175/JCLI-D-12-00837.1. 
Huang, B., and Coauthors, 2017: Extended Reconstructed Sea Surface Temperature, version 5 (ERSSTv5): Upgrades, validations, and intercomparisons. J. Climate, 30, 8179-8205, https://doi.org/10.1175/JCLI-D-16-0836.1.

Imada, Y., H. Tatebe, M. Watanabe, M. Ishii, and M. Kimoto, 2016: South Pacific influence on the termination of El Niño in 2014. Sci. Rep., 6, 30341, https://doi.org/10.1038/srep30341.

Jin, F.-F., 1996: Tropical ocean-atmosphere interaction, the Pacific cold tongue, and the El Niño-Southern Oscillation. Science, 274, 76-78, https://doi.org/10.1126/science.274.5284.76.

- 1997: An equatorial ocean recharge paradigm for ENSO. Part I: Conceptual model. J. Atmos. Sci., 54, 811-829, https://doi.org/ 10.1175/1520-0469(1997)054<0811:AEORPF>2.0.CO;2.

— J. J. Neelin, and M. Ghil, 1994: El Niño on the devil's staircase: Annual subharmonic steps to chaos. Science, 264, 70-72, https://doi.org/10.1126/science.264.5155.70.

—, S.-I. An, A. Timmermann, and J. Zhao, 2003: Strong El Niño events and nonlinear dynamical heating. Geophys. Res. Lett., 30, 1120, https://doi.org/10.1029/2002GL016356.

_, S. T. Kim, and L. Bejarano, 2006: A coupled-stability index for ENSO. Geophys. Res. Lett., 33, L23708, https://doi.org/ 10.1029/2006GL027221.

Kim, S.-T., and F.-F. Jin, 2011a: An ENSO stability analysis. Part I: Results from a hybrid coupled model. Climate Dyn., 36, 15931607, https://doi.org/10.1007/s00382-010-0796-0.

—, and - 2011b: An ENSO stability analysis. Part II: Results from the twentieth and twenty-first century simulations of the CMIP3 models. Climate Dyn., 36, 1609-1627, https://doi.org/ 10.1007/s00382-010-0872-5.

—, W. Cai, F.-F. Jin, A. Santoso, L. Wu, E. Guilyardi, and S.-I. An, 2014: Response of El Niño sea surface temperature variability to greenhouse warming. Nat. Climate Change, 4, 786790, https://doi.org/10.1038/nclimate2326.

Kohyama, T., and D. L. Hartmann, 2017: Nonlinear ENSO warming suppression (NEWS). J. Climate, 30, 4227-4251, https://doi.org/10.1175/JCLI-D-16-0541.1.

Koutavas, A., P. B. deMenocal, G. C. Olive, and J. Lynch-Stieglitz, 2006: Mid-Holocene El Niño-Southern Oscillation (ENSO) attenuation revealed by individual foraminifera in eastern tropical Pacific sediments. Geology, 34, 993-996, https:// doi.org/10.1130/G22810A.1.

Liang, J., X.-Q. Yang, and D.-Z. Sun, 2017: Factors determining the asymmetry of ENSO. J. Climate, 30, 6097-6106, https:// doi.org/10.1175/JCLI-D-16-0923.1.

Liu, Z., and S.-P. Xie, 1994: Equatorward propagation of coupled air-sea disturbances with application to the annual cycle of the eastern tropical Pacific. J. Atmos. Sci., 51, 3807-3822, https:// doi.org/10.1175/1520-0469(1994)051<3807:EPOCAD>2.0.CO;2.

— J. Kutzbach, and L. Wu, 2000: Modeling climate shift of El Niño variability in the Holocene. Geophys. Res. Lett., 27, 2265-2268, https://doi.org/10.1029/2000GL011452.

_- E. Brady, and J. Lynch-Stieglitz, 2003: Global ocean response to orbital forcing in the Holocene. Paleoceanography, 18, 1041, https://doi.org/10.1029/2002PA000819.

— Z. Lu, X. Wen, B. L. Otto-Bliesner, A. Timmermann, and K. M. Cobb, 2014: Evolution and forcing mechanisms of El Niño over the past 21,000 years. Nature, 515, 550-553, https:// doi.org/10.1038/nature13963.

Lu, P., J. P. McCreary, and B. A. Klinger, 1998: Meridional circulation cells and the source waters of the Pacific Equatorial Undercurrent. J. Phys. Oceanogr., 28, 62-84, https:// doi.org/10.1175/1520-0485(1998)028<0062:MCCATS > 2.0.CO;2.
Lu, Z., and Z. Liu, 2019: Orbital modulation of ENSO seasonal phase locking. Climate Dyn., 52, 4329-4350, https://doi.org/ 10.1007/s00382-018-4382-1.

,$- \ldots$, J. Zhu, and K. M. Cobb, 2018: A review of paleo El Niño-Southern Oscillation. Atmosphere, 9, 130, https://doi.org/ 10.3390/atmos9040130.

Luan, Y., P. Braconnot, Y. Yu, W. Zheng, and O. Marti, 2012: Early and mid-Holocene climate in the tropical Pacific: Seasonal cycle and interannual variability induced by insolation changes. Climate Past, 8, 1093-1108, https://doi.org/10.5194/ cp-8-1093-2012.

Maes, C., M. J. McPhaden, and D. Behringer, 2002: Signatures of salinity variability in tropical Pacific Ocean dynamic height anomalies. J. Geophys. Res., 107, 8012, https://doi.org/10.1029/ $2000 J C 000737$.

Meehl, G. A., P. R. Gent, J. M. Arblaster, B. L. Otto-Bliesner, E. C. Brady, and A. Craig, 2001: Factors that affect the amplitude of El Niño in global coupled climate models. Climate Dyn., 17, 515-526, https://doi.org/10.1007/PL00007929.

Otto-Bliesner, B. L., E. C. Brady, S.-I. Shin, Z. Liu, and C. Shields, 2003: Modeling El Niño and its tropical teleconnections during the last glacial-interglacial cycle. Geophys. Res. Lett., 30, 2198, https://doi.org/10.1029/2003GL018553.

Pausata, F. S. R., and Coauthors, 2017: Greening of the Sahara suppressed ENSO activity during the mid-Holocene. Nat. Commun., 8, 16020, https://doi.org/10.1038/ncomms16020.

Rayner, N. A., D. E. Parker, E. B. Horton, C. K. Folland, L. V. Alexander, D. P. Rowell, E. C. Kent, and A. Kaplan, 2003: Global analyses of sea surface temperature, sea ice, and night marine air temperature since the late nineteenth century. J. Geophys. Res., 108, 4407, https://doi.org/10.1029/ 2002JD002670.

Rein, B., A. Lückge, L. Reinhardt, F. Sirocko, A. Wolf, and W.-C. Dullo, 2005: El Niño variability off Peru during the last 20,000 years. Paleoceanography, 20, PA4003, https://doi.org/10.1029/ 2004PA001099.

Roberts, W. H. G., D. S. Battisti, and A. W. Tudhope, 2014: ENSO in the mid-Holocene according to CSM and HadCM3. J. Climate, 27, 1223-1242, https://doi.org/10.1175/ JCLI-D-13-00251.1.

Santer, B. D., and Coauthors, 2018: Human influence on the seasonal cycle of tropospheric temperature. Science, 361, eaas 8806 , https://doi.org/10.1126/science.aas8806.

Schneider, N., A. J. Miller, M. A. Alexander, and C. Deser, 1999: Subduction of decadal North Pacific temperature anomalies: Observations and dynamics. J. Phys. Oceanogr., 29, 1056-1070, https://doi.org/10.1175/1520-0485(1999)029<1056: SODNPT $>2.0 . \mathrm{CO} ; 2$.

Stein, K., A. Timmermann, N. Schneider, F.-F. Jin, and M. F. Stuecker, 2014: ENSO seasonal synchronization theory. J. Climate, 27, 5285-5310, https://doi.org/10.1175/JCLI-D-13-00525.1.

Steinke, S., M. Mohtadi, M. Prange, V. Varma, D. Pittauerova, and H. W. Fischer, 2014: Mid- to late-Holocene AustralianIndonesian summer monsoon variability. Quat. Sci. Rev., 93, 142-154, https://doi.org/10.1016/j.quascirev.2014.04.006.

Stommel, H., 1979: Determination of water mass properties of water pumped down from the Ekman layer to the geostrophic flow below. Proc. Natl. Acad. Sci. USA, 76, 3051-3055, https:// doi.org/10.1073/pnas.76.7.3051.

Stuecker, M. F., F.-F. Jin, A. Timmermann, and S. McGregor, 2015: Combination mode dynamics of the anomalous northwest Pacific anticyclone. J. Climate, 28, 1093-1111, https://doi.org/ 10.1175/JCLI-D-14-00225.1. 
Su, J., R. Zhang, T. Li, X. Rong, J.-S. Kug, and C.-C. Hong, 2010: Causes of the El Niño and La Niña amplitude asymmetry in the equatorial eastern Pacific. J. Climate, 23, 605-617, https:// doi.org/10.1175/2009JCLI2894.1.

Sun, Y., F. Wang, and D.-Z. Sun, 2016: Weak ENSO asymmetry due to weak nonlinear air-sea interaction in CMIP5 climate models. Adv. Atmos. Sci., 33, 352-364, https://doi.org/10.1007/ s00376-015-5018-6.

Takahashi, C., and M. Watanabe, 2016: Pacific trade winds accelerated by aerosol forcing over the past two decades. Nat. Climate Change, 6, 768-772, https://doi.org/10.1038/nclimate2996.

Taylor, K. E., R. J. Stouffer, and G. A. Meehl, 2012: An overview of CMIP5 and the experiment design. Bull. Amer. Meteor. Soc., 93, 485-498, https://doi.org/10.1175/BAMS-D-11-00094.1.

Timmermann, A., F.-F. Jin, and J. Abshagen, 2003: A nonlinear theory for El Niño bursting. J. Atmos. Sci., 60, 152-165, https:/doi.org/ 10.1175/1520-0469(2003)060<0152:ANTFEN > 2.0.CO;2.

_, and Coauthors, 2018: El Niño-Southern Oscillation complexity. Nature, 559, 535-545, https://doi.org/10.1038/s41586-018-0252-6.

Tziperman, E., L. Stone, M. A. Cane, and H. Jarosh, 1994: El Niño chaos: Overlapping of resonances between the seasonal cycle and the Pacific ocean-atmosphere oscillator. Science, 264, 7274, https://doi.org/10.1126/science.264.5155.72.

Watanabe, M., and Coauthors, 2010: Improved climate simulation by MIROC5: Mean states, variability, and climate sensitivity. J. Climate, 23, 6312-6335, https://doi.org/10.1175/ 2010JCLI3679.1.

, M. Chikira, Y. Imada, and M. Kimoto, 2011: Convective control of ENSO simulated in MIROC. J. Climate, 24, 543562, https://doi.org/10.1175/2010JCLI3878.1.

, H. Shiogama, H. Tatebe, M. Hayashi, M. Ishii, and M. Kimoto, 2014: Contribution of natural decadal variability to global warming acceleration and hiatus. Nat. Climate Change, 4, 893-897, https://doi.org/10.1038/nclimate2355.

Williams, R., M. Spall, and J. Marshall, 1995: Does Stommel's mixed layer "demon" work? J. Phys. Oceanogr., 25, 30893102, https://doi.org/10.1175/1520-0485(1995)025<3089: DSMLW $>2.0 . \mathrm{CO} ; 2$.

Zheng, W., P. Braconnot, E. Guilyardi, U. Merkel, and Y. Yu, 2008: ENSO at $6 \mathrm{ka}$ and $21 \mathrm{ka}$ from ocean-atmosphere coupled model simulations. Climate Dyn., 30, 745-762, https://doi.org/ 10.1007/s00382-007-0320-3. 